\title{
Caveolin-1 regulation of Sp1 controls production of the antifibrotic protein follistatin in kidney mesangial cells
}

Neel Mehta ${ }^{1}$, Dan Zhang ${ }^{1}$, Renzhong Li ${ }^{1}$, Tony Wang ${ }^{1}$, Agata Gava², Pavithra Parthasarathy ${ }^{1}$, Bo Gao ${ }^{1}$ and Joan C. Krepinsky ${ }^{1,3^{*}}$ (D)

\begin{abstract}
Background: We previously showed that caveolin-1 (cav-1), an integral membrane protein, is required for the synthesis of matrix proteins by glomerular mesangial cells (MC). In a previous study to understand how cav-1 is involved in regulating matrix production, we had identified significant upregulation of the antifibrotic protein follistatin in cav-1 knockout MC. Follistatin inhibits the profibrotic effects of several members of the transforming growth factor beta superfamily, in particular the activins. Here, we characterize the molecular mechanism through which cav-1 regulates the expression of follistatin.
\end{abstract}

Methods: Kidneys from cav-1 wild type and knockout (KO) mice were analyzed and primary cultures of MC from cav-1 wild-type and KO mice were utilized. FST promoter deletion constructs were generated to determine the region of the promoter important for mediating FST upregulation in cav-1 KO MC. siRNA-mediated downregulation and overexpression of Sp1 in conjunction with luciferase activity assays, immunoprecipitation, western blotting and ChiP was used to assess the role of Sp1 in transcriptionally regulating FST expression. Pharmacologic kinase inhibitors and specific siRNA were used to determine the post-translational mechanism through which cav-1 affects Sp1 activity.

Results: Our results establish that follistatin upregulation occurs at the transcript level. We identified Sp1 as the critical transcription factor regulating activation of the FST promoter in cav-1 KO MC through binding to a region within $123 \mathrm{bp}$ of the transcription start site. We further determined that the lack of cav-1 increases Sp1 nuclear levels and transcriptional activity. This occurred through increased phosphoinositide 3-kinase (PI3K) activity and downstream protein kinase C (PKC) zeta-mediated phosphorylation and activation of Sp1.

Conclusions: These findings shed light on the transcriptional mechanism by which cav-1 represses the expression of a major antifibrotic protein, and can inform the development of novel antifibrotic treatment strategies.

Keywords: Caveolin-1, Mesangial cells, Follistatin, Sp1, Renal fibrosis

\section{Background}

Mesangial cells $(\mathrm{MC})$ are specialized pericytes involved in the production and secretion of mesangial matrix within glomeruli of kidneys [1-3]. The mesangial matrix serves to anchor $\mathrm{MC}$ and provide structural support and integrity to the surrounding

\footnotetext{
*Correspondence: krepinj@mcmaster.ca

${ }^{1}$ Division of Nephrology, Department of Medicine, McMaster University, Hamilton, Canada

${ }^{3}$ St. Joseph's Hospital, 50 Charlton Ave East, Rm T3311, Hamilton, ON L8N 4A6, Canada

Full list of author information is available at the end of the article
}

glomerular capillaries [1-3]. Under homeostatic conditions, MC secrete matrix that is composed of collagens, laminin and fibronectin $[1,4-6]$. The activation and transition of $\mathrm{MC}$ to a more secretory myofibroblastic phenotype has been established to be an early fibrogenic response in kidney disease of varying etiology, including that due to diabetes and hypertension [1-7].

Caveolae are small (50-100 nm) glycosphingolipid- and cholesterol-enriched omega-shaped invaginations of the plasma membrane that are involved in mediating a wide

(C) The Author(s). 2019 Open Access This article is distributed under the terms of the Creative Commons Attribution 4.0 International License (http://creativecommons.org/licenses/by/4.0/), which permits unrestricted use, distribution, and 
array of signaling transduction events [8-10]. Through compartmentalization of signaling proteins, caveolae can either positively or negatively mediate signal transduction [8-10]. The caveolin (cav) gene family consists of three proteins, cav-1, cav-2 and cav- 3 . Cav- 1 and cav- 2 are ubiquitously expressed, whereas cav-3 is limited to skeletal muscle, diaphragm, and heart [8-10]. Formation of caveolae requires cav-1, a $21-24 \mathrm{kDa}$ integral membrane protein [8-10]. We have previously shown that the ability of $\mathrm{MC}$ to produce matrix proteins both basally and in response to profibrotic stimuli such as transforming growth factor beta beta 1 (TGF $\beta 1$ ), mechanical stress, and high glucose is dependent on cav-1 expression [11-13]. Importantly, diabetic mice lacking cav-1 are protected against mesangial matrix expansion and the development of glomerular sclerosis [11]. Strong upregulation of cav-1 has also been demonstrated in rodent models of chronic kidney disease and diabetic nephropathy [10, 14]. These studies support a profibrotic role for cav-1/caveolae in kidney fibrosis.

Clinically targeting cav-1 in vivo is challenging [10]. Thus, to better understand how cav-1 elimination reduces matrix production in $\mathrm{MC}$, and more importantly, to identify potential novel therapeutically applicable targets that can be exploited to overcome the difficulties associated with directly targeting cav-1, our lab previously identified and measured the expression of potential anti-fibrotic candidates that are altered in cav-1 deficient MC. Of primary interest, we identified significant upregulation of follistatin (FST), an anti-fibrotic factor, in MC lacking cav-1.

FST is an ubiquitously expressed and secreted glycoprotein that binds to and neutralizes the profibrotic and proinflammatory actions of several TGF $\beta$ superfamily members, with greatest activity against activins $[15$, 16]. We and others have shown that FST acts as a strong antifibrotic agent in various organs, including the kidneys in models of obstructive kidney damage and diabetic nephropathy (Aoki et al., [17]; Patella et al.,[18]; Maeshima et al.,[19]; Zhang et al., Kidney Int, submitted).

The molecular mechanism through which FST is regulated by cav-1 in glomerular $\mathrm{MC}$ is as yet unknown. Here, we show that signaling through the phosphoinositide 3-kinase (PI3K), protein kinase C zeta (PKC $)$ and Sp1 signaling pathway is augmented in cav-1 deficient MC to increase the transcriptional regulation of FST. These findings shed insight into the molecular mechanism through which cav-1 regulates the expression of FST and provide important knowledge that can inform the development of antifibrotic treatment strategies for chronic kidney disease.

\section{Methods}

\section{Cell culture}

Primary mouse MC were isolated from male cav-1 wild-type (WT) and cav-1 knockout (KO) B6129SF1/J mice (Jackson Laboratory) using Dynabeads (Invitrogen). Briefly, mice were perfused with magnetic Dynabeads, kidneys were harvested and digested by collagenase and glomeruli were collected using a magnet. Isolated glomeruli were washed with HBSS, resuspended in Dulbecco's modified Eagle's medium supplemented with $20 \%$ fetal bovine serum (Invitrogen), penicillin $(100 \mu \mathrm{g} / \mathrm{ml})$ and streptomycin $(100 \mu \mathrm{g} / \mathrm{ml})$ at $37^{\circ} \mathrm{C}$ in $95 \% \mathrm{O}_{2}, 5 \% \mathrm{CO}_{2}$. $\mathrm{MC}$ were grown out, with passages 7-14 used for experiments. MC were serum deprived in $0.5 \%$ FBS $24 \mathrm{~h}$ prior to all treatments unless otherwise stated. Drugs/reagents used in the study are provided in Additional file 1: Table S1.

\section{Transfection}

$\mathrm{MC}$ at $60-70 \%$ confluence were transfected $(0.5 \mu \mathrm{g}$ luciferase plasmid with $0.05 \mu \mathrm{g} \beta$-galactosidase or $1-2 \mu \mathrm{g}$ protein expression plasmid) using Effectene (Qiagen) as per the manufacturer's recommendation. siRNA-mediated knockdown was achieved using RNAiMAX (Thermo Fisher Scientific) as per the manufacturer's recommendation. Plasmids and siRNA used in the study are provided in Additional file 1: Table S2.

\section{Luciferase assay}

MC lysis was achieved using Reporter Lysis Buffer (Promega) as per the manufacturer's recommendation. Luciferase activity was measured on clarified cell lysate using the Luciferase Assay System (Promega) with a luminometer (Junior LB 9509, Berthold). $\beta$-galactosidase activity, used to normalize for transfection efficiency, was measured in clarified cell lysates using the $\beta$-Galactosidase Enzyme Assay System (Promega) with a plate reader absorbance set at $420 \mathrm{~nm}$ (SpectraMax Plus 384 Microplate Reader, Molecular Devices).

\section{Protein extraction, immunoprecipitation and immunoblotting}

MC cell lysis and protein extraction were carried out as described previously [20]. Briefly, cell lysates were centrifuged $\left(15,000 \mathrm{rpm}, 10 \mathrm{~min}, 4^{\circ} \mathrm{C}\right)$, supernatant was collected and protein concentration quantified. For immunoprecipitation experiments, cells were lysed, clarified and equal amounts of lysate were immunoprecipitated using $1 \mu \mathrm{g}$ primary antibody (18 $\mathrm{h}, 4^{\circ} \mathrm{C}$ ), followed by incubation with protein-G-agarose slurry $\left(2 \mathrm{~h}, 4{ }^{\circ} \mathrm{C}\right)$. Cell protein lysates $(10 \mu \mathrm{g}-$ $50 \mu \mathrm{g}$ ) and immunoprecipitated products (total yield) were separated on SDS-PAGE for subsequent immunoblotting. Antibodies used in the study are provided in Additional file 1: Table S3. 


\section{Quantitative-real time PCR}

RNA from MC was extracted using Ribozol RNA Extraction Reagent (Amresco) as per the manufacturer's recommendation, with $1 \mu \mathrm{g}$ of RNA reverse transcribed into cDNA using qScript cDNA SuperMix Reagent (Quanta Biosciences). Quantitative real-time PCR was carried out using the Power SYBR Green PCR Master Mix (Thermo Fisher Scientific) on the Applied Biosystems ViiA 7 Real-Time PCR System (Thermo Fisher Scientific). mRNA expression and fold changes were calculated using the $\Delta \Delta C_{T}$ method, where $18 \mathrm{~S}$ was used as the endogenous control. Primer sequences used in the study are provided in Additional file 1: Table S4.

\section{ChIP}

At endpoint, $\mathrm{MC}$ were cross-linked using formaldehyde (10 min, RT), neutralized using $1 \mathrm{M}$ glycine ( $\mathrm{pH}$ 2.2) (5 $\mathrm{min}, \mathrm{RT}$ ), resuspended in ice-cold PBS containing protease inhibitors and centrifuged $\left(13,000 \mathrm{rpm}, 5 \mathrm{~min}, 4^{\circ} \mathrm{C}\right)$. The cell pellet was resuspended in nuclear extraction buffer (20 mM HEPES pH 7.9, 25\% glycerol, $420 \mathrm{mM}$ $\mathrm{NaCl}, 1.5 \mathrm{mM} \mathrm{MgCl}, 0.2 \mathrm{mM}$ EDTA, protease inhibitors), incubated on ice $(20 \mathrm{~min})$ and centrifuged $(13,000 \mathrm{rpm}$, $\left.10 \mathrm{~min}, 4^{\circ} \mathrm{C}\right)$. The resulting nuclear pellet was resuspended in Breaking Buffer (50 mM Tris- $\mathrm{HCl}$ pH 8.0, 1 mM EDTA, $150 \mathrm{mM} \mathrm{NaCl}, 1 \%$ SDS, 2\% Triton X-100, protease inhibitors), sonicated $6 \times 3 \mathrm{~s}$, and Triton Buffer added (50 mM Tris- $\mathrm{HCl} \mathrm{pH}$ 8.0, $1 \mathrm{mM}$ EDTA, $150 \mathrm{mM}$ $\mathrm{NaCl}, 0.1 \%$ Triton $\mathrm{X}-100$ ). $10 \%$ of the original aliquot was collected (input) and the rest used for immunoprecipitation for Sp1 and mouse IgG (as described above). Immunoprecipitated samples were washed $3 \mathrm{x}$ in Triton Buffer. SDS Buffer was then added $(62.5 \mathrm{mM}$ Tris $\mathrm{HCl}$ $\mathrm{pH} 6.8,200 \mathrm{mM} \mathrm{NaCl}, 2 \% \mathrm{SDS}, 10 \mathrm{mM}$ DTT, $2 \mu \mathrm{l}$ of proteinase $\mathrm{K}(40 \mathrm{mg} / \mathrm{ml}))$ and samples incubated $\left(18 \mathrm{~h}, 65^{\circ}\right.$ C) to reverse crosslinking. DNA was isolated using phenol/chloroform extraction and resuspended in $\mathrm{dH}_{2} \mathrm{O}$. qRT-PCR was used, as described above, to amplify the purified DNA using primers specific to the Sp1 binding site located within $-123 \mathrm{bp}$ of the mouse FST (mFST) promoter. $\mathrm{Ct}$ values were evaluated across multiple replicate experiments using the \%input method, where \%input $=100 * 2$ (Adjusted input - Ct (IP)) .

\section{Cloning}

The full-length mouse FST luciferase (-luc) construct, mFST4-FL-luc, (obtained from Dr. Jeong Yoon) containing the mouse FST promoter with exon 1 and intron 1 was digested with KpnI and NheI. The resulting product was inserted into a linearized pGL3-luc vector in order to generate a construct which lacks intron 1 and most of exon $1(+20 \mathrm{bp}$ is included, where transcription start site $=+1)$. The resulting plasmid hereafter is referred to as mFST4-luc. mFST4-luc was used to generate mFST promoter deletion constructs using the primer sequences listed in Additional file 1: Table S5.

Two Sp1 binding sites (CCGCCC) localized within the mFST4-123 bp promoter were deleted in order to generate mFST4 $\Delta$ intron1-123 $\Delta$ Sp1-luc. Briefly, oligonucleotides coding the FST-123 promoter sequence lacking the two Sp1 binding sites along with the KpnI (5') and NheI( $\left.3^{\prime}\right)$ digestion sites were synthesized, annealed, and ligated into pGL3-Basic luc. All sequences synthesized for cloning are listed in Additional file 1: Table S5. All generated constructs were confirmed by sequencing (Mobix Lab, McMaster University).

\section{PI3K activity assay}

A plasmid encoding a Venus-tagged pleckstrin homology (PH) domain of Akt (PH-Akt-Venus), a gift from Dr. Narasimhan Gautam (Addgene plasmid \# 85223), was transfected into MC. Plasma membrane localization of the $\mathrm{PH}$ domain of Akt was used as a live phosphatidylinositol 3,4,5-trisphosphate (PIP3) sensor for assessing PI3K activity [21]. Briefly, $24 \mathrm{~h}$ following transfection, cav-1 WT and $\mathrm{KO} \mathrm{MC}$ were incubated with wheat germ agglutinin (WGA) Alexa Fluor-594 Conjugate (Thermo Scientific) in HBSS $\left(2 \mu \mathrm{g} / \mathrm{ml}, 10 \mathrm{~min}, 37^{\circ}\right.$ C) to delineate the plasma membrane. After plasma membrane labeling, MC were washed and images were taken using a fluorescein (ex490nm/em525nm) and rhodamine (ex550nm/em620nm) filter sets (EVOS FL Cell Imaging System, Thermo Fisher Scientific). Image J, in conjunction with the co-localization finder plugin (https://imagej.nih.gov/ij/plugins/colocalization-finder.

html), was used to create colocalization masks and quantify the percent localization of PH-Akt-Venus to the cell membrane.

\section{Immunohistochemistry/immunocytochemistry}

Cav-1 WT and KO B6129SF1/J mice were sacrificed and perfused with cold PBS in accordance with principles of laboratory animal care and McMaster University and Canadian Council on Animal Care guidelines. For immunohistochemistry, $4 \mu \mathrm{m}$ FFPE kidney sections were deparaffinized, endogenous peroxidase activity was blocked, and heat-induced epitope retrieval was carried out for immunohistological staining. Briefly, tissues were blocked with $5 \%$ horse serum and incubated in primary antibody overnight at $4 \mathrm{C}$. Tissues were then incubated with biotinylated secondary antibodies (Vector Labs) (30 min, room temperature) and then incubated with streptavidin/peroxidase (30 min, room temperature) (Vector Labs). Chromogenic color development was carried out using Nova Red (Vector Labs), followed by counterstaining using Gill's hematoxylin (Sigma), and mounting in a xylene based mounting media (Permount; Thermo Scientific). All micrographs were captured at $x$ 
200 and $\times 400$ magnification using the BX41 Olympus microscope. The total percentage of positive area (signal) within the kidneys was measured using ImageJ.

Serum deprived MC plated in an 8-well chamber slide were used for ICC. Cells were fixed in $4 \%$ paraformaldehyde, permeabilized in $0.2 \%$ Triton X-100, blocked in $1 \%$ $\mathrm{BSA} / 3 \%$ donkey serum, and incubated with primary antibodies overnight at $4 \mathrm{C}$. Cells were then incubated with Alex-Fluor (Thermo Scientific) conjugated secondary antibodies (30 min, room temperature, dark), and mounted and counterstained using a DAPI-containing fluorescent mounting media (Vector Labs). All ICC micrographs were captured using the fluorescein (ex490nm/em525nm) and DAPI (ex350nm/em470nm) filter sets (EVOS FL Cell Imaging System, Thermo Fisher Scientific). Mean fluorescence intensity within the nucleus, delineated using DAPI and/or total cellular expression examined under the appropriate fluorescence filter sets was measured using ImageJ.

\section{Statistical analysis}

Statistical analyses were performed using GraphPad Prism 6. A Student's $t$-test or one-way ANOVA was used to determine statistical significance between two or more groups, respectively. Post hoc significance of pairwise comparisons was assessed using Tukey's HSD. A $p$-value $<0.05$ (two-tailed) was considered significant. Data are presented as mean \pm SEM. The number of experimental repetitions $(n)$ is indicated in the figure captions.

\section{Results}

\section{Cav-1 regulation of FST occurs at the transcript level in MC}

We have identified FST as a significantly upregulated gene in cav-1 deficient MC compared to their wild-type (WT) counterparts. Figure 1 shows elevated FST expression at the mRNA (Fig. 1a) and protein level (Fig. 1b) in cultured primary cav-1 KO MC. It should be noted that the FST antibody detects two main bands in MC. Using FST siRNA, we confirm that these are both FST (Fig. 1c). This is likely due to the presence of different isoforms and/or differentially glycosylated forms of the protein [22-25]. Increased FST expression is also seen in the kidneys of mice lacking cav-1 compared to WT mice (Fig. 1d). Confirming the anti-fibrotic properties of FST in $\mathrm{MC}$, TGF- $\beta 1$-mediated extracellular matrix protein (ECM) production was blunted by the addition of recombinant FST in cav-1 WT MC (Additional file 2: Figure S1A). Conversely, FST downregulation using siRNA significantly augmented TGF- $\beta 1$-medited ECM production in cav-1 KO MC (Additional file 2: Figure S1B). These results confirm that FST inhibits TGF- $\beta$-induced ECM production in MC.
To identify potential avenues by which cav-1 regulates FST expression, we began by examining stability of the FST transcript in cav-1 WT and KO MC. Using actinomycin D to stop de novo transcription, we observed that FST mRNA has a half-life of about $4 \mathrm{~h}$ which was unaffected by cav-1 expression (Fig. 1e). We next assessed whether FST protein stability was affected by cav-1. Using cycloheximide to prevent de novo protein synthesis, we determined that FST has a rapid turnover rate, which is also unaffected by cav-1 expression (Fig. 1f). The increased transcript and protein levels seen in cav-1 $\mathrm{KO} \mathrm{MC}$ are thus not a result of increased post-transcriptional mRNA stability or post-translational protein stability.

We next sought to determine whether cav-1 regulates FST expression at the transcriptional level. The mouse FST promoter has been previously characterized [26]. Using a mouse FST promoter luciferase reporter construct, we assessed whether FST promoter activity was differentially regulated in cav-1 WT and KO MC. Here, we found significantly elevated transcriptional activity in cav-1 KO MC of both mFST4-FL-luc, which also contains intron 1 and exon 1 of FST, and mFST4-luc in which these are removed (Fig. 2a and b). Since removal of intron 1 and exon 1 did not affect cav-1 KO upregulation of FST promoter activity, we used mFST4-luc as a template to generate promoter deletion constructs ranging from $-1840 \mathrm{bp}$ to $-123 \mathrm{bp}$ upstream of the transcription start site (TSS) (Fig. 2c). Here, we surprisingly found significantly elevated transcriptional activity of all promoter deletion constructs in cav-1 KO MC (Fig. 2d). These data illustrate that transcriptional regulatory elements residing between $-123 \mathrm{bp}$ and the TSS of the mouse FST promoter are critical for the upregulation of FST that is observed in cav-1 KO MC. Next, using siRNA-mediated cav-1 downregulation in cav-1 WT $\mathrm{MC}$, we confirmed that cav-1 was directly involved in the regulation of FST promoter activity (Fig. 2e) and protein expression (Fig. 2f). However, the relative increase in FST transcription and expression upon cav-1 downregulation with siRNA was not as effective in comparison to the elevation seen in cav-1 KO MC. This is likely due to differences in the degree of cav-1 suppression between these two approaches.

\section{Cav-1 transcriptionally regulates FST through Sp1}

Having established a transcriptional effect of cav-1 on the -123 bp FST promoter, we next screened for transcription factor regulatory element(s) located within this region. Putative transcription factor binding sites within the mFST promoter were identified using MatInspector and PROMO [27]. Interestingly, we identified two Sp1 binding sites (CCGCCC) in this region (Fig. 3a), with Sp1 having been shown to regulate FST promoter 


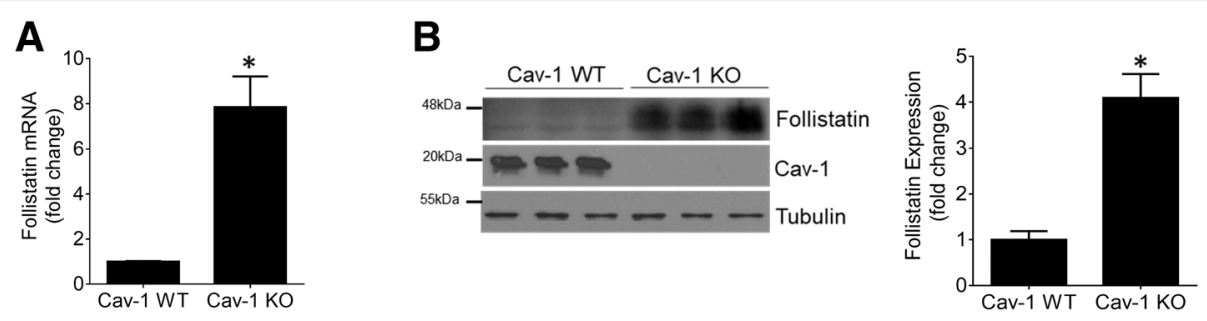

\section{C}

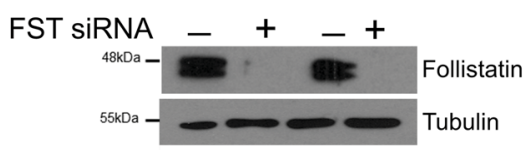

E

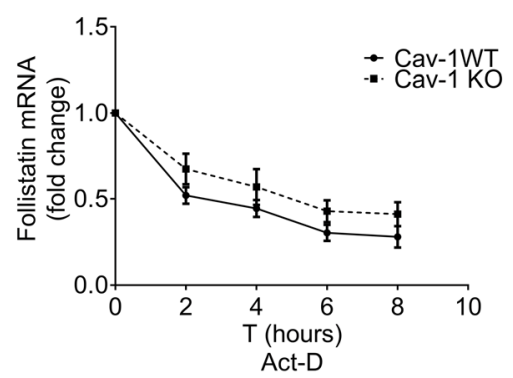

$\mathbf{F}$

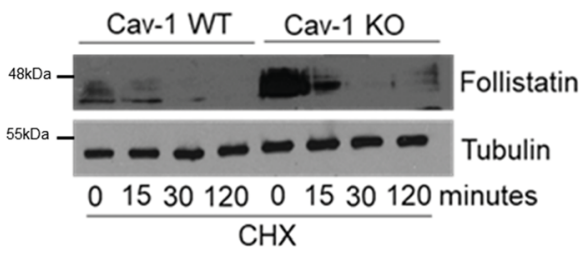

D
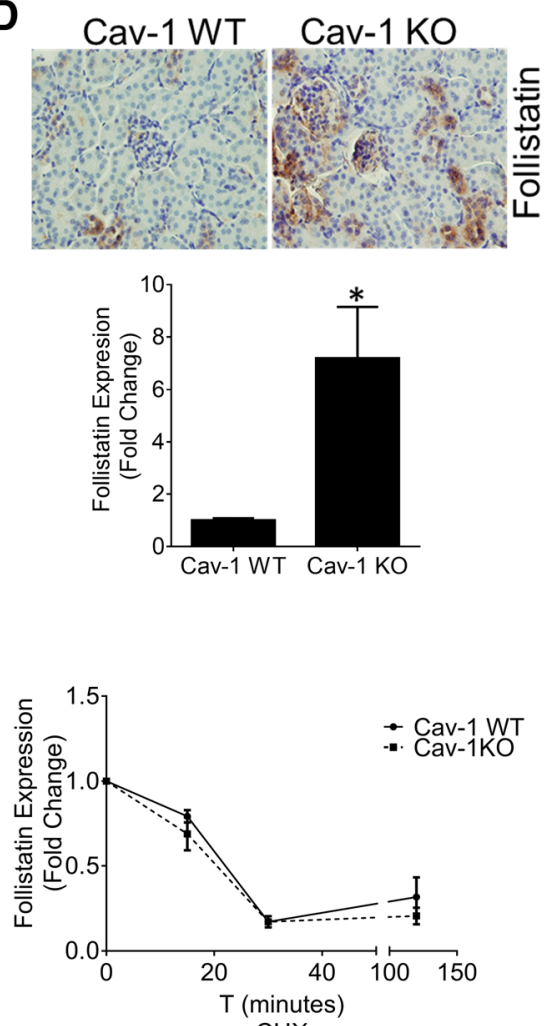

$\mathrm{CHX}$

Fig. 1 Cav-1 transcriptionally represses FST. In primary cav-1 KO MC, FST expression was increased at both the transcript level $\left(n=12,{ }^{*} p<0.05\right)$ (a) and protein level $\left(n=9,{ }^{*} p<0.05\right)(\mathbf{b})$. c Immunoblotting after FST downregulation with siRNA showed the specificity of the FST antibody in cav-1 KO MC $(n=2)$. d FST was elevated in the kidneys of cav-1 KO mice $\left(n=4\right.$ mice, ${ }^{*} p<0.05$, representative micrographs shown). e MC were treated with the transcriptional inhibitor actinomycin $D(1 \mu \mathrm{g} / \mathrm{ml})$, and FST transcript assessed at the indicated times. FST mRNA stability did not differ between cav-1 WT and KO MC $(n=5)$. $\mathbf{f ~ C a v - 1 ~ W T ~ a n d ~ K O ~ M C ~ w e r e ~ t r e a t e d ~ w i t h ~ t h e ~ t r a n s l a t i o n a l ~ i n h i b i t o r ~ c y c l o h e x i m i d e ~}(10 \mu \mathrm{g} / \mathrm{ml})$, and FST protein assessed at the indicated times. FST protein stability was not altered by cav-1 KO $(n=3)$

activity in intestinal epithelial cells [28]. We thus assessed its role in mediating FST upregulation in cav-1 KO MC. We first determined whether Sp1 levels are altered in these cells. To this end, we found elevated Sp1 expression in cav-1 KO MC (Fig. 3b). This was associated with increased $\mathrm{Sp} 1$ nuclear presence, as assessed by immunoblotting (Fig. 3c) and immunofluorescence (Fig. 3d), as well as increased transcriptional activity as measured using a Sp1-target sequence binding luciferase (Fig. 3e). Similar increases of $\mathrm{Sp} 1$ expression and nuclear localization were seen in both glomeruli and tubules of cav-1
KO mice (Fig. 3f). Next, using siRNA-mediated cav-1 downregulation in WT MC, we confirmed the regulation of Sp1 activity by cav-1 (Fig. 3g).

Our next studies aimed to determine whether $\mathrm{Sp} 1$ is a major regulator of FST transcription in cav-1 KO MC. We first assessed if Sp1 overexpression can increase the transcriptional activity of the $-123 \mathrm{bp}$ mouse FST promoter. Figure $4 \mathrm{a}$ shows that the overexpressed $\mathrm{Sp} 1$ is functionally active, effectively increasing $\mathrm{Sp} 1$ transcriptional activity. In cav-1 WT MC, Sp1 overexpression also significantly increased FST promoter transcriptional activity (Fig. 4b), showing a prominent role for Sp1 in 

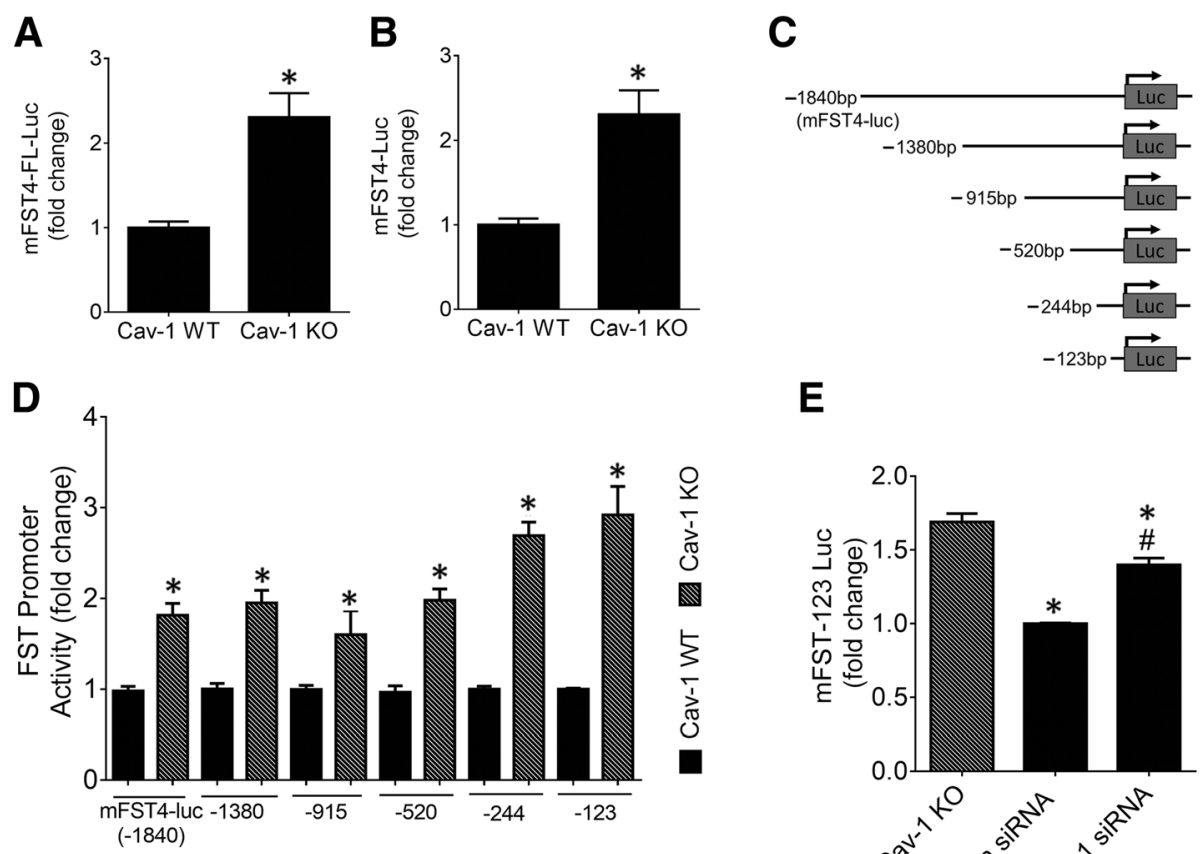

E
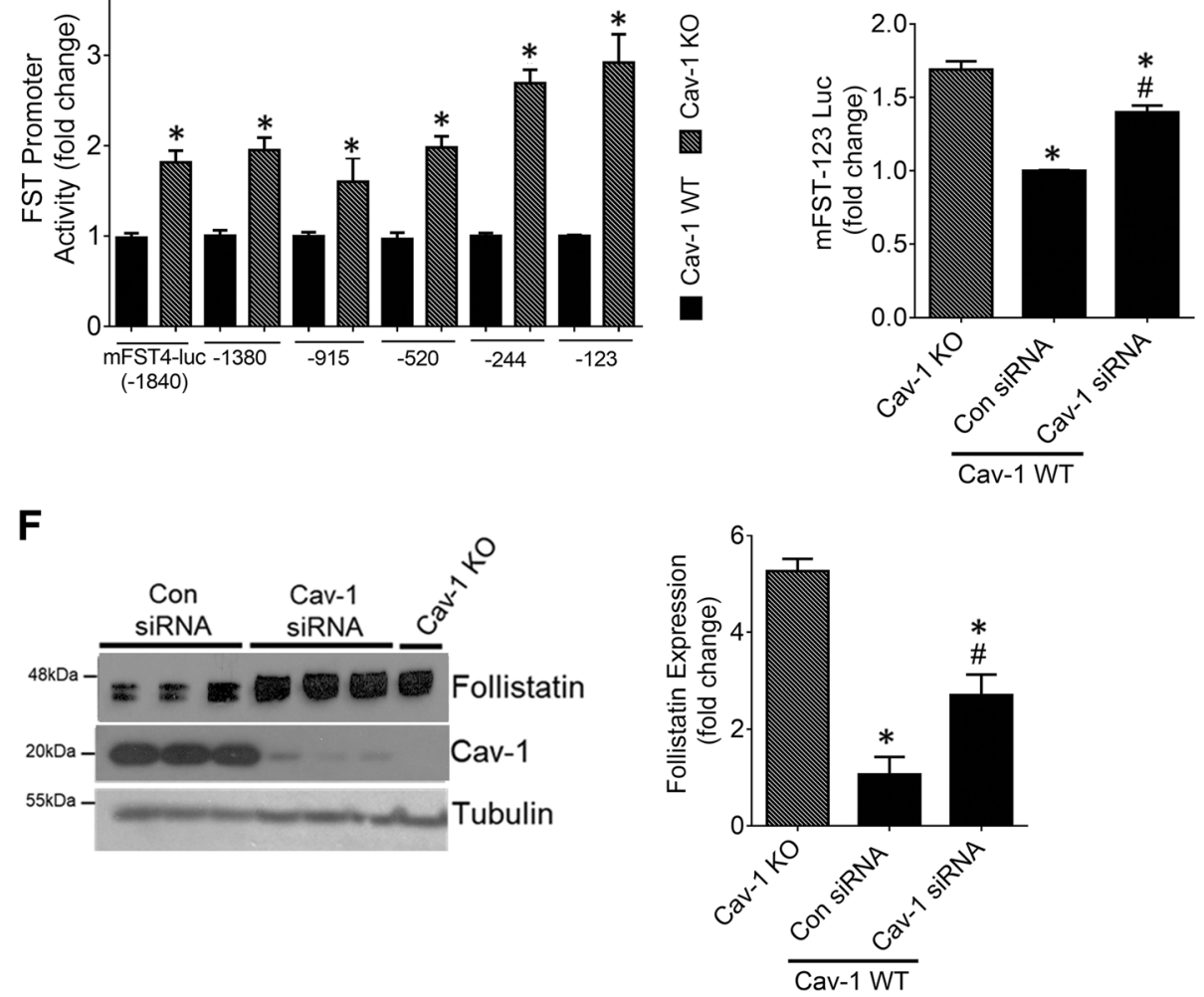

Fig. 2 Cav-1 regulates activity of the FST promoter. Cav-1 WT and KO MC were transfected with (a) the full-length FST promoter luciferase construct or (b) the full-length FST promoter luciferase construct lacking intron 1 and exon 1. KO MC exhibited significantly elevated transcriptional activity of both constructs $\left(n=6,{ }^{*} p<0.05\right)$. c Graphical representation of the synthesized FST promoter deletion constructs. $\mathbf{d}$ Cav$1 \mathrm{WT}$ and KO MC were transfected with the FST promoter deletion constructs shown in (C). Transcriptional activation of all constructs was elevated in cav-1 KO MC ( $n=6-20,{ }^{*} p<0.05$ vs WT for each construct). e, f Cav-1 knockdown in WT MC significantly increased the transcriptional activation of the -123 bp FST promoter (e) and FST protein expression (f) compared with control siRNA-transfected KO MC (for both, $n=6,{ }^{*} \mathrm{Vs}$ $\mathrm{KO}, \#$ V $W T$ con siRNA, $p<0.05)$

FST promoter regulation. We then downregulated Sp1 using siRNA to assess whether it is essential for the increased FST seen in cav-1 KO MC. Figure 4c confirms the successful knockdown of Sp1. As we hypothesized, Sp1 knockdown reduced FST promoter transcriptional activity in KO MC to levels seen in WT cells (Fig. 4d). FST mRNA and protein expression were similarly reduced (Fig. 4e, f). A smaller decrease in protein levels was also observed in cav-1 WT cells, demonstrating the importance of Sp1 to basal FST regulation.
We next wished to confirm that Sp1 binds to the FST - 123 promoter region. Using ChIP coupled with qRT-PCR, we quantified the amount of Sp1 binding to the putative Sp1 binding sites localized within the $-123 \mathrm{bp}$ promoter region of FST. As seen in Fig. 4g, Sp1 binding in this region was significantly more abundant in cav-1 KO compared to WT MC. To confirm that this is required for transcriptional regulation of FST, we deleted the two identified Sp1 binding sites within the $-123 \mathrm{bp}$ region of the FST promoter 

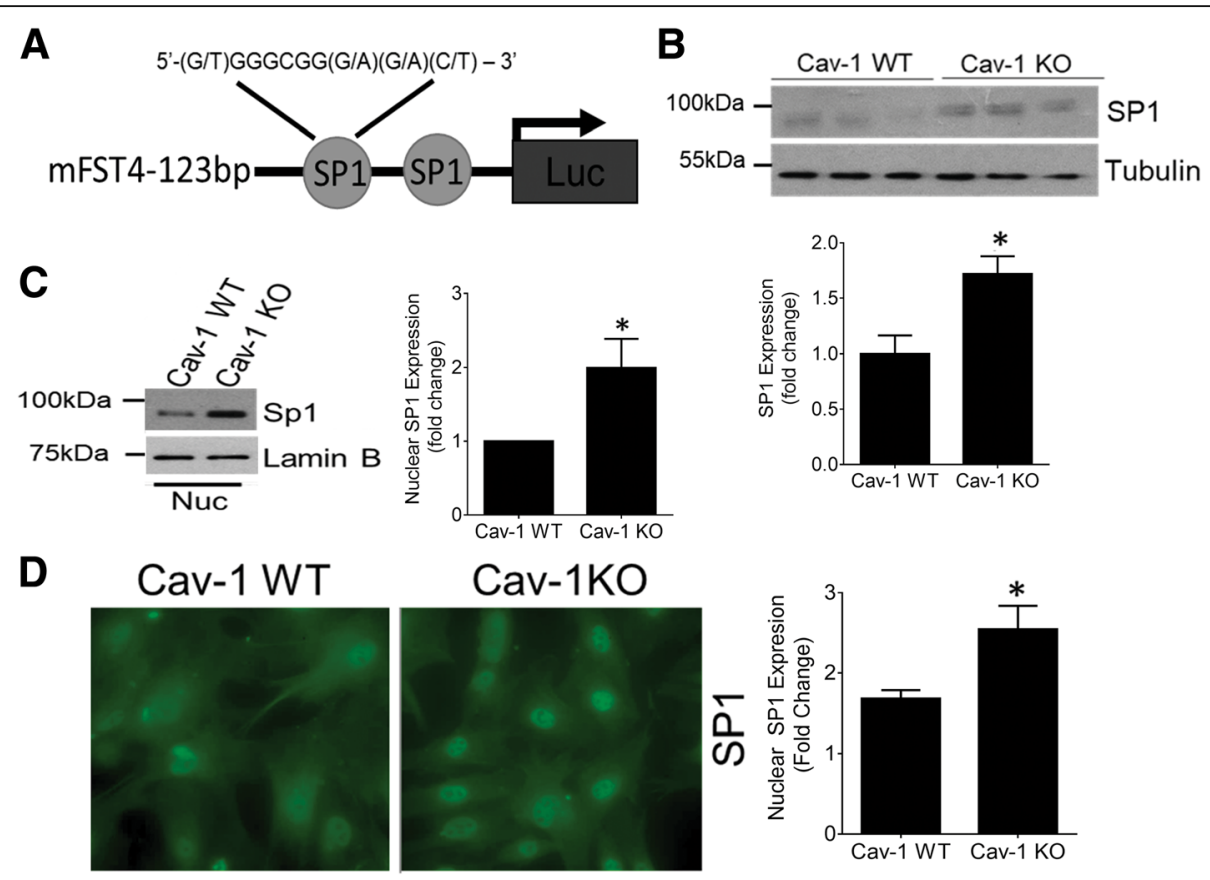

$\mathbf{E}$

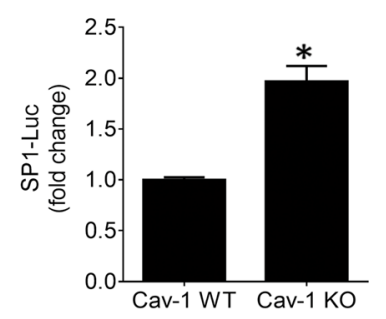

$\mathbf{F}$

G
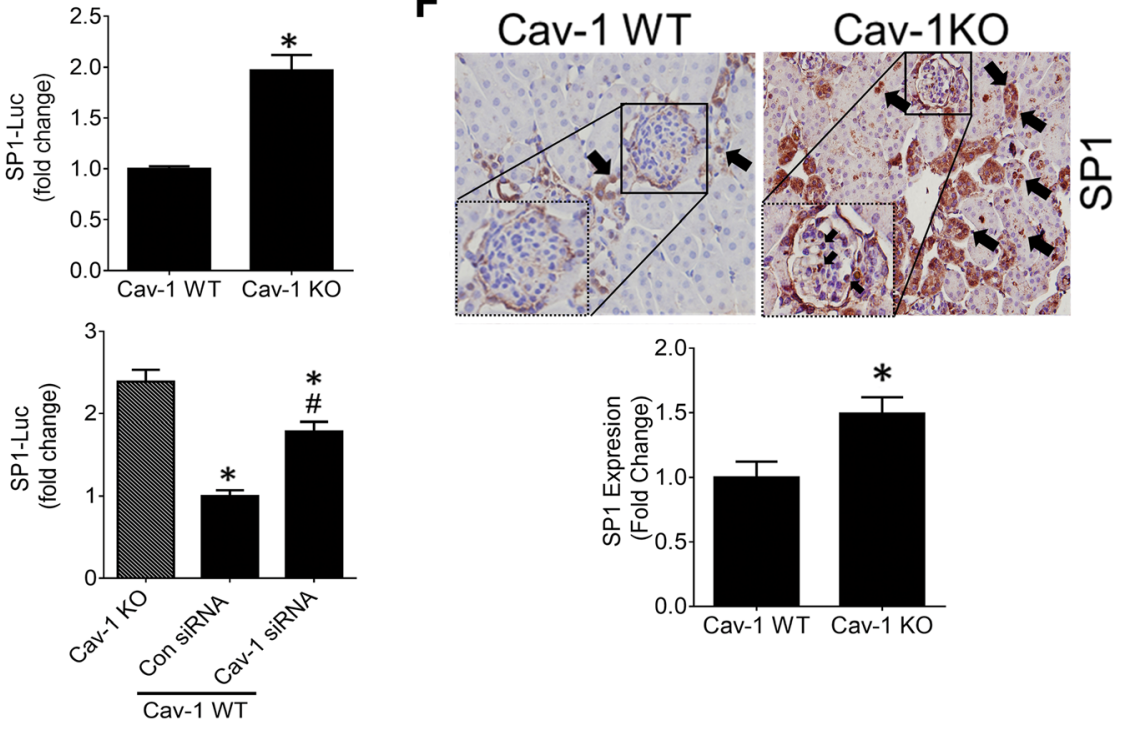

Fig. 3 Sp1 expression and activity are elevated by cav-1 deletion. a Predicted Sp1 transcription factor binding sites within the -123 bp region of the FST promoter are shown. Sp1 protein expression was significantly increased in cav-1 KO compared to WT MC as assessed by western blotting of total cell lysate $\left(n=12,{ }^{*} p<0.05\right)(\mathbf{b})$ and nucleus $\left(n=5,{ }^{*} p<0.05\right)(\mathbf{c})$, as well as by immunofluorescence microscopy $\left(n=5,{ }^{*} p<0.05\right.$, representative micrographs shown) (d). e Sp1 activity, as assessed by the Sp1 reporter construct Sp1-luc, was elevated in cav-1 KO MC ( $n=16$, ${ }^{*} p<0.05$ ). $\mathbf{f} \mathrm{Sp} 1$ expression and nuclear localization (arrows) were elevated in the kidneys of cav-1 KO mice, seen in both glomeruli (magnified glomerular area shown within dotted box) and tubules ( $n=3$ mice, ${ }^{*} p<0.05$, representative micrographs shown). g Cav-1 knockdown in WT MC significantly increased Sp1 activity compared with control siRNA-transfected KO MC ( $n=6$, *vs KO, \#vs WT con siRNA, $p<0.05)$

(Fig. 4h). Deletion of both of these resulted in a significant decrease in FST promoter activity in both cav-1 WT and KO MC. Importantly, the elevated FST promoter activity observed in cav-1 KO compared with WT MC was abolished, highlighting the central role for $\mathrm{Sp} 1$ in FST transcriptional regulation by cav-1 (Fig. 4i). The decrease seen in WT MC additionally illustrates the importance of $\mathrm{Sp} 1$ to basal FST regulation. Taken together, these data show an important regulatory role for cav-1 in $\mathrm{Sp} 1$ expression and transcriptional activity, which leads to a significant upregulation of FST in cav-1 KO cells. 
A

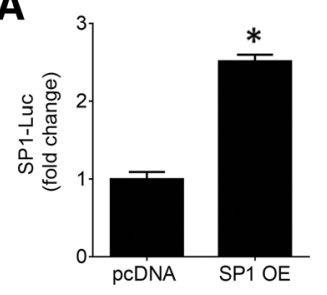

D
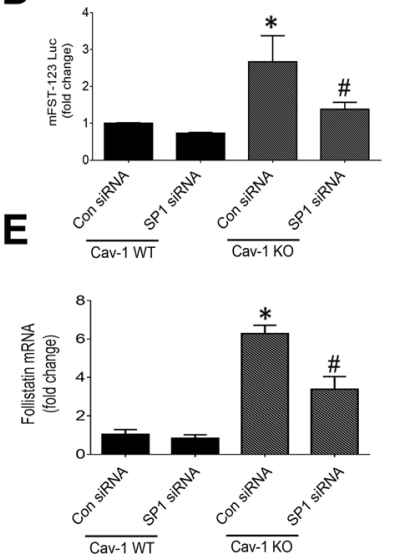

H

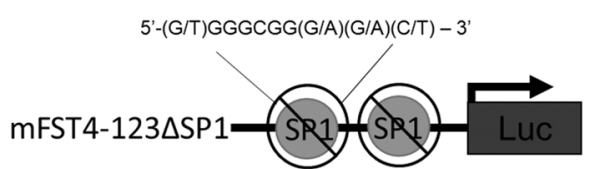

F

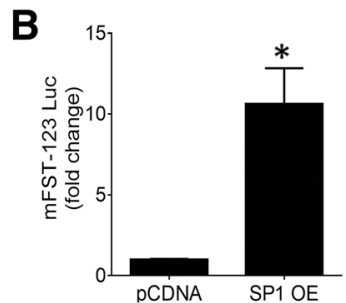

C
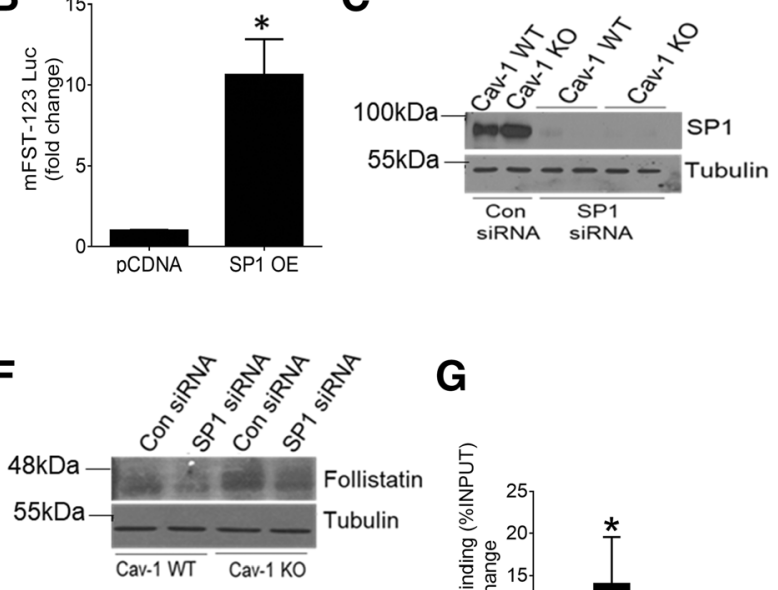

G
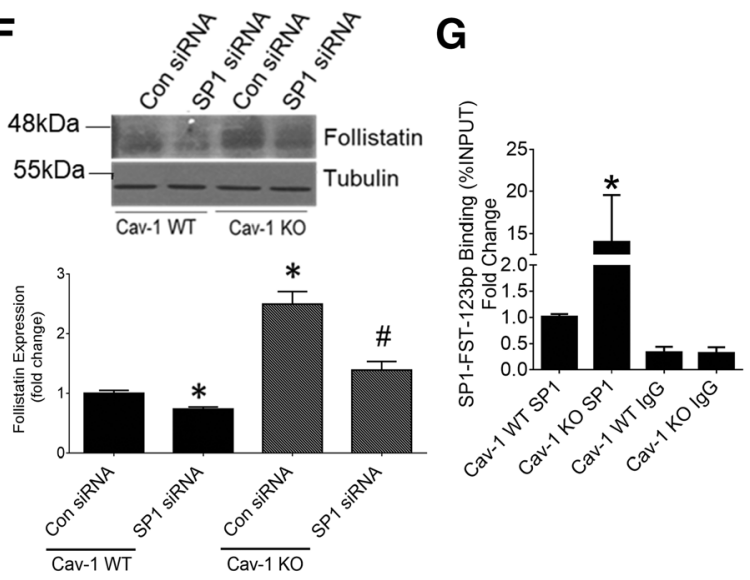

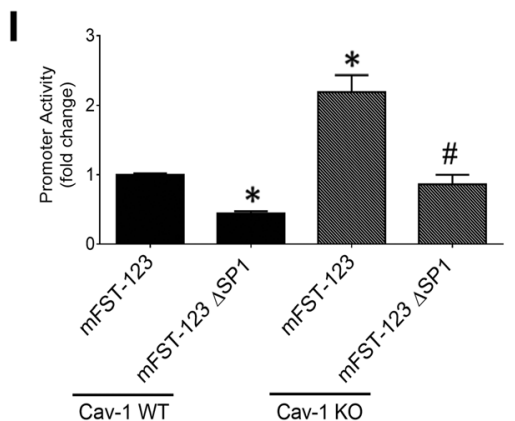

Fig. 4 Sp1 binds the -123 bp region of the FST promoter to regulate its activity. Expression of constitutively active Sp1 in cav-1 WT MC increased activity of both the Sp1 reporter construct $(\mathbf{a})\left(n=3,{ }^{*} p<0.05\right)$ and mFST-123-luc (b) $\left(n=6,{ }^{*} p<0.05\right)$. c Effective siRNA-mediated Sp1 knockdown in cav-1 WT and KO MC was confirmed by immunoblotting. $\mathbf{d}$ Sp1 knockdown abolished the increased transcriptional activity of the -123 bp FST promoter in cav-1 KO MC, with little effect in WT cells $\left(n=6,{ }^{*} v\right.$ s WT con siRNA, \#vs KO con siRNA, $\left.p<0.05\right)$. e Sp1 knockdown repressed the elevation in FST mRNA expression in cav-1 KO MC ( $n=3$, *vs WT con siRNA, \#vs KO con siRNA, $p<0.05)$. f Similar effects of Sp1 knockdown on FST protein expression were seen $\left(n=4,{ }^{*}\right.$ vs WT con siRNA, \#vS KO con siRNA, $\left.p<0.05\right)$. g Sp1 binding within the -123 bp region of the FST promoter at the predicted Sp1 binding sites was significantly elevated in cav-1 KO MC as assessed by ChIP $(n=14, p<0.05)$. $\mathbf{h}$ Graphical representation of the deletion of the two predicted Sp1 binding sites within the -123 bp promoter region of FST (mFST4-123 $\Delta$ Sp1-Iuc). i Deletion of the two Sp1 binding sites attenuated transcriptional activity of mFST4-123-luc in cav-1 WT and normalized activity in cav-1 KO MC to levels seen in WT cells $(n=9$, *vs WT mFST-123-luc, \#vs KO mFST-123-luc, $p<0.05$ )

\section{Cav-1 regulates Sp1 activity through PI3K and PKCC}

The regulation of $\mathrm{Sp} 1$ by cav-1 has not previously been described. We thus wanted to determine the mechanism underlying this observation. It is well known that Sp1 activity is under tight regulation via phosphorylation, which can either positively or negatively influence the activity and binding of $\mathrm{Sp} 1$ to its downstream targets [29]. Since serine/threonine (ser/ thr) phosphorylation of $\mathrm{Sp} 1$ by various kinases was shown to be an important stimulator of Splactivity, we compared baseline Sp1 ser/thr phosphorylation between cav-1 KO and WT cells. After Sp1 was immunoprecipitated from total cell lysate, immunoblotting for phosphorylated ser/thr sites showed a greater degree of Sp1 ser/thr phosphorylation in cav-1 KO MC (Fig. 5a).

Next, we sought to identify the kinase responsible for increased Sp1 phosphorylation in cav-1 KO MC. Using 

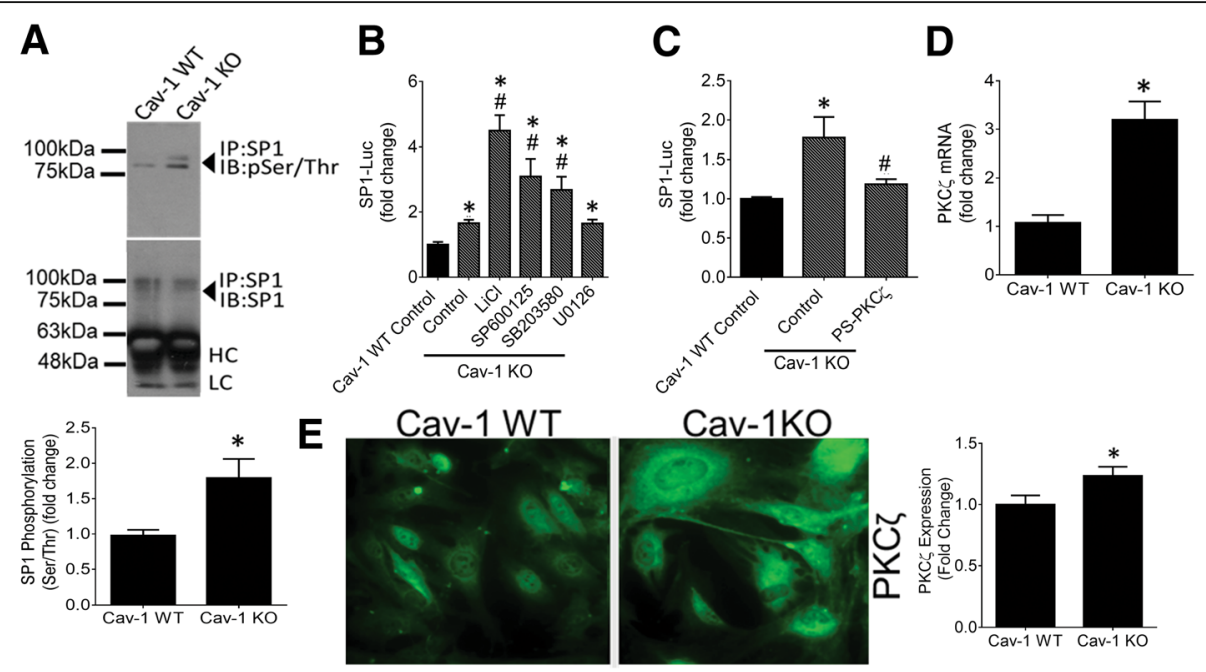

$\mathbf{F}$

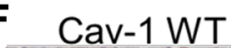

Cav-1KO
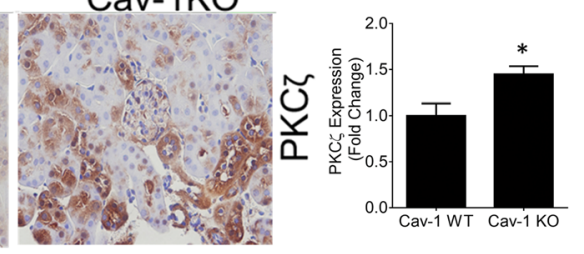

G
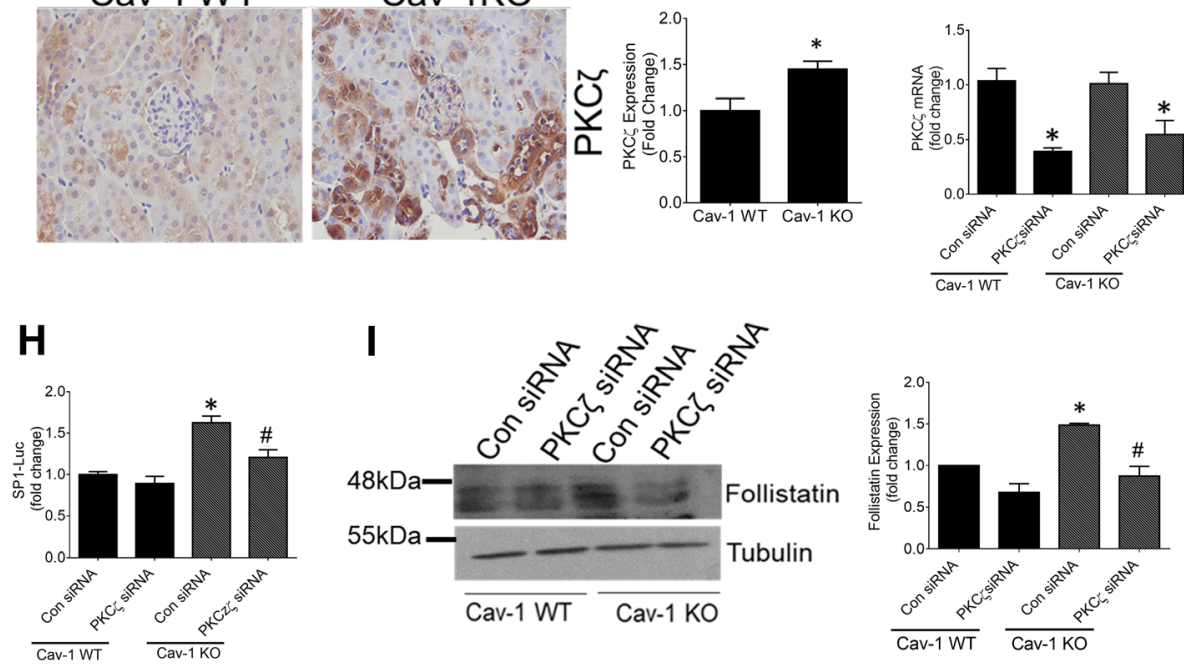

Fig. 5 Increased PKC induces Sp1 activity to upregulate FST in cav-1 KO MC. a Sp1 was immunoprecipitated from cav-1 WT and KO MC and immunoblotted for serine/threonine phosphorylation. Elevated phosphorylation was seen in KO cells ( $n=3$, representative blots shown). b None of the following kinase inhibitors reduced Sp1 activity, assessed using the Sp1 reporter construct, to that seen in WT cells: GSK3 $\beta$ inhibitor LiCl

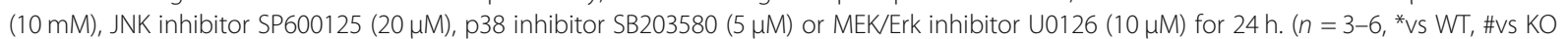

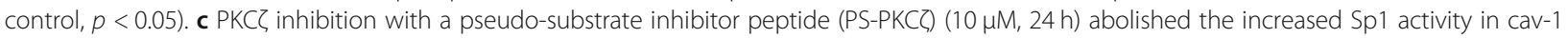
KO MC $\left(n=9,{ }^{*}\right.$ vs WT, \# vs KO control, $\left.p<0.05\right)$. d PKC MRNA $\left(n=3,{ }^{*} p<0.05\right)$ and $(\mathbf{e})$ protein expression $\left(n=2,{ }^{*} p<0.05\right.$, representative micrographs shown) was significantly elevated in cav-1 KO MC. $\mathbf{f}$ PKC expression was elevated in the kidneys of cav-1 KO mice in both tubules and glomeruli ( $n=3$ mice, ${ }^{*} p<0.05$, representative micrographs shown). $\mathbf{g}$ Effective siRNA-mediated PKC knockdown was confirmed by qRTPCR in cav- 1 WT and KO MC ( $n=3,{ }^{*} p<0.05$ vs con siRNA for both WT and KO MC normalized to their own controls). $\mathbf{h}, \mathbf{i}$ PKC knockdown reduced both the increased Sp1 activity (h) and FST protein expression (i) in KO MC to levels seen in WT cells (G: $n=9$, *Vs WT con siRNA, \# vs KO con siRNA, $p<0.05 ; \mathrm{H}: n=3$, *vs WT con siRNA, \#vs KO con siRNA, $p<0.05$ )

various inhibitors, we screened kinases known to phosphorylate Sp1 at ser/thr residues and thereby enhance Sp1 activity. Figure $5 \mathrm{~b}$ shows that in cav-1 KO MC, glycogen synthase kinase 3 beta (GSK $\beta$ ) (using LiCl), c-Jun N-terminal kinase (JNK) (using SP600125) and p38 mitogen-activated protein kinase (MAPK) (using SB203580) inhibition significantly upregulated Sp1 activity, while mitogen-activated protein kinase kinase (MEK) inhibition (using U0126) did not affect Sp1 activity.
None of these kinases are thus responsible for the upregulation of Sp1 activity in cav-1 KO MC.

We next assessed the role of protein kinase $\mathrm{C}$ zeta (PKC)), which has been shown in numerous cell types to phosphorylate and positively regulate $\mathrm{Sp} 1$ activity [30]. We found that $\mathrm{PKC}$ inhibition using a $\mathrm{PKC} \zeta$ pseudosubstrate reduced the increased activity of Sp1 in cav-1 $\mathrm{KO} \mathrm{MC}$ to WT levels (Fig. 5c). We then questioned whether the expression of $\mathrm{PKC \zeta}$ is altered in cav-1 
deficient MC. Interestingly, both PKCל mRNA (Fig. 5d) and protein (Fig. 5e) were significantly increased in cav-1 KO MC. Upregulation of РКC $\zeta$ expression was also observed in the glomeruli and tubules of cav-1 $\mathrm{KO}$ mice (Fig. 5f). To further confirm the role of PKC $\zeta$ as an upstream regulator of the increased Sp1 activity seen in cav-1 KO cells, we downregulated PKC $\zeta$ using siRNA. Figure 5g shows effective PKC $\zeta$ knockdown in cav-1 WT and KO MC. Similar to pharmacologic inhibition, this reduced Sp1 activity in cav-1 KO MC to levels seen in WT cells (Fig. 5h). Accompanying decreases in FST protein expression were also seen (Fig. 5i).

PI3K was shown to be an important promoter of PKC $\zeta$ activity in numerous cell types [30]. To assess the importance of PI3K-mediated activation of PKCל in $\mathrm{Sp} 1$ activation and thereby FST regulation in cav-1 $\mathrm{KO} \mathrm{MC}$, we examined the effects of two distinct PI3K inhibitors. Both of these (wortmannin and LY294002) significantly reduced Sp1 activity in cav-1 $\mathrm{KO} \mathrm{MC}$ to that seen in WT cells (Fig. 6a), although LY249002 was more efficacious than wortmannin in this regard. This may be due to the greater stability of LY294002 in solution [31]. Akt is a ser/thr kinase well-known to be activated by PI3K [32]. However, the Akt inhibitor VIII did not reduce $\mathrm{Sp} 1$ activity in $\mathrm{KO}$ cells. This is in keeping with a known role for the enzyme phosphoinositide-dependent protein kinase-1 (PDK-1) and not Akt as the kinase downstream of PI3K which phosphorylates and activates PKCद [33].

We next tested the effects of PI3K inhibition on FST mRNA and protein expression. PI3K inhibition significantly reduced FST mRNA expression in cav-1 KO MC (Fig. 6b). Figure 6c similarly shows that, in cav-1 KO MC, PI3K inhibition reduced FST protein expression to levels seen in WT cells. Last, we assessed whether cav-1 KO MC have increased PI3K activity. Here, we transfected cav-1 WT and KO MC with a fluorescent biosensor (Ph-Akt-Venus) for phosphatidylinositol 3,4,5-trisphosphate (PIP3) [21]. Class I PI3Ks are responsible for the production of PIP3 at the plasma membrane. Thus, the translocation of the pleckstrin homology (Ph) domain of Akt to the plasma membrane is indicative of PIP3 generation and can serve as a readout of enzymatic PI3K activity. A fluorophore-labeled wheat germ agglutinin (WGA) was used to label the plasma membrane to confirm localization. Figure $6 \mathrm{~d}$ shows a pronounced increase in PI3K activity in cav-1 KO MC, identified by colocalization of Ph-Akt-VENUS and WGA and highlighted using a colocalization mask (seen in white). Quantification of the colocalization mask is shown in the accompanying graph. Collectively, as summarized in Fig. 7, our results show that cav-1 deficient MC exhibit increased activity of PI3K, an upstream regulator of $\mathrm{PKC} \zeta$ activity. Increased $\mathrm{PKC \zeta}$ activity results in elevated $\mathrm{Sp} 1$ activation which augments FST transcription.

\section{Discussion}

Our previous studies have identified a critical role for cav-1 in the ability of MC to produce extracellular matrix proteins and profibrotic cytokines, both basally and in response to profibrotic stimuli [11-13]. Increased cav-1 expression has been observed in several fibrotic kidney diseases in both animal models and humans [14, 34-36]. Furthermore, studies using cav-1 knockout mice and cav- 1 deficient cells have shown that the elimination of cav-1 can protect against fibrosis both in vivo and in vitro, while having no adverse effects on blood pressure and renal function [10,11, 13, 37]. As of now, targeting cav-1 via therapeutic approaches has not been feasible. In our efforts to better understand how cav-1 deficient $\mathrm{MC}$ are protected against the profibrotic effects of several stimuli relevant to chronic kidney disease such as high glucose, TGF $\beta 1$ and mechanical stress [11-13], we identified significant upregulation of the antifibrotic protein FST in mouse MC lacking cav-1. Functionally, we show that inhibiting the expression of FST in cav-1 KO $\mathrm{MC}$ restored matrix production both basally and in response to profibrotic stimuli and that supplementing exogenous FST in cav-1 WT MC protected against matrix protien production. We also identified the mechanism by which cav-1 deficiency led to FST upregulation. Our data now identify a novel role for cav-1 in controlling activity of the transcription factor $\mathrm{Sp1}$, a critical regulator of FST transcription in MC. We further provide mechanistic insight into Sp1 regulation by cav-1, showing that this occurs at the post-translational level through control of PI3K-PKC signaling. Figure 7 highlights our proposed molecular mechanism through which cav-1 regulates expression of the antifibrotic protein FST in glomerular mesangial cells. These findings carry important implications for the potential use of therapies targeting this pathway in the treatment of chronic kidney disease, as discussed below.

Interestingly, a related follistatin-domain containing protein, follistatin-like 3 (FSTL-3), has been shown to protect against matrix production in $\mathrm{MC}$ exposed to high glucose [38]. FSTL-3 functions similarly to FST, binding and neutralizing similar TGF $\beta$ superfamily family members. However, it is distinct from FST due to the absence of a heparin binding motif, preventing its binding to cell surface heparan-sulfate proteoglycans as occurs with FST $[39,40]$. Thus, differences in in vivo biologic activities between FSTL-3 and FST likely exist. We did not find any differences in FSTL-3 transcript expression in cav-1 WT and KO MC (Additional file 3: Figure S2), thus excluding a major contribution of 
A

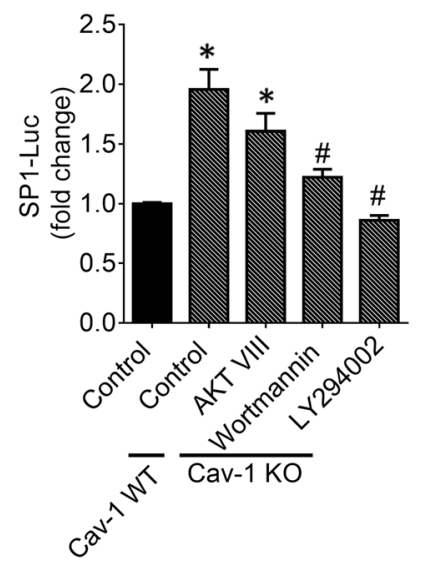

C

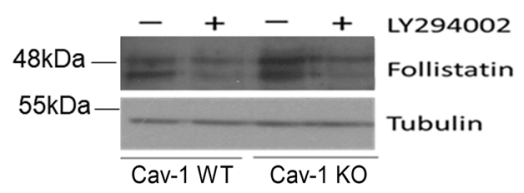

D
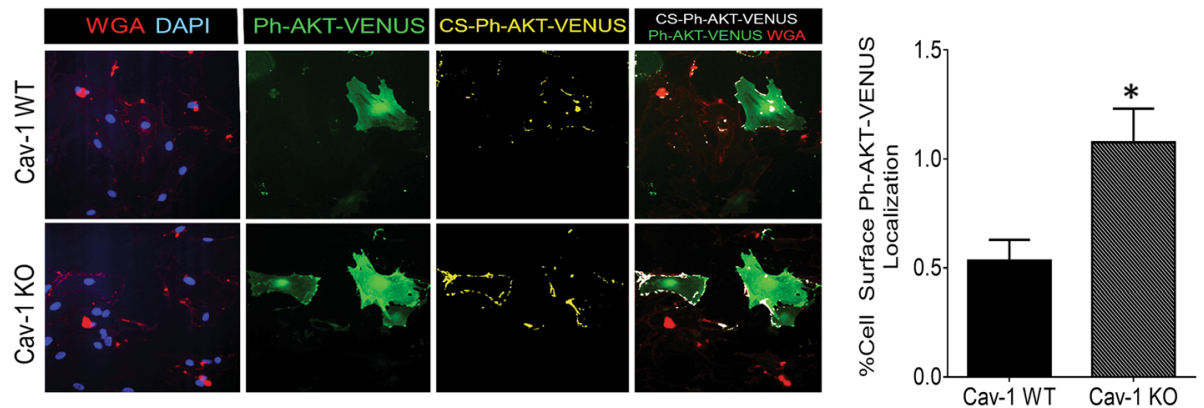

Fig. 6 PI3K is a caveolin-1-regulated mediator of PKCZ required for FST upregulation in cav-1 KO MC. a The PI3K inhibitors wortmannin (500 nM)

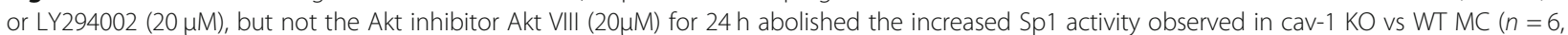
*vs WT, \# vs KO control, $p<0.05)$. b PI3K inhibition prevented the increase in FST mRNA expression observed in cav-1 KO MC ( $n=5$, *vs WT, \#vs $\mathrm{KO}$ control, $p<0.05)$. c PI3K inhibition also abolished the increased FST protein expression observed in cav- $1 \mathrm{KO}$ vs WT MC ( $n=4$, ${ }^{*}$ Vs WT, \#VS KO control, $p<0.05$ ). d Cav-1 WT and KO MC were transfected with the fluorescent PIP3 biosensor PH AKT-Venus (green). Elevated basal PI3K activity, as observed by increased PIP3 production at the plasma membrane, delineated by WGA (red), was seen in cav-1 KO MC. This is highlighted by the white co-localization mask ( $n=3,21$ micrographs quantified, with representative micrographs shown)

FSTL-3 to the antifibrotic phenotype we observed in cav-1 KO MC.

Several transcription factors have thus far been found to regulate FST expression in different cell types, including CREB, Smad3 and $\beta$-catenin $[28,41-43]$. Sp1, a ubiquitously expressed transcription factor, was also noted to activate the FST promoter in intestinal epithelial cells [28]. Our findings in MC support an important role for $\mathrm{Sp} 1$ in regulation of the FST promoter, and further identify elevated Sp1 activity as the mechanism by which cav-1 deletion leads to FST upregulation. Interestingly, we found that only a very short segment $(123 \mathrm{bp})$ of the proximal promoter, containing two Sp1 binding sites, regulates FST promoter activity both basally and in response to cav-1 deletion. Concurrent with our findings, a region 262 bp upstream of the translation start site was previously shown to be critical for the regulation of FST expression in a manner reflecting endogenous mRNA expression [26].

How $\mathrm{Sp} 1$ activity is regulated by cav- 1 is not as yet understood. It is well known, however, that it is under tight regulation via numerous post-translational 


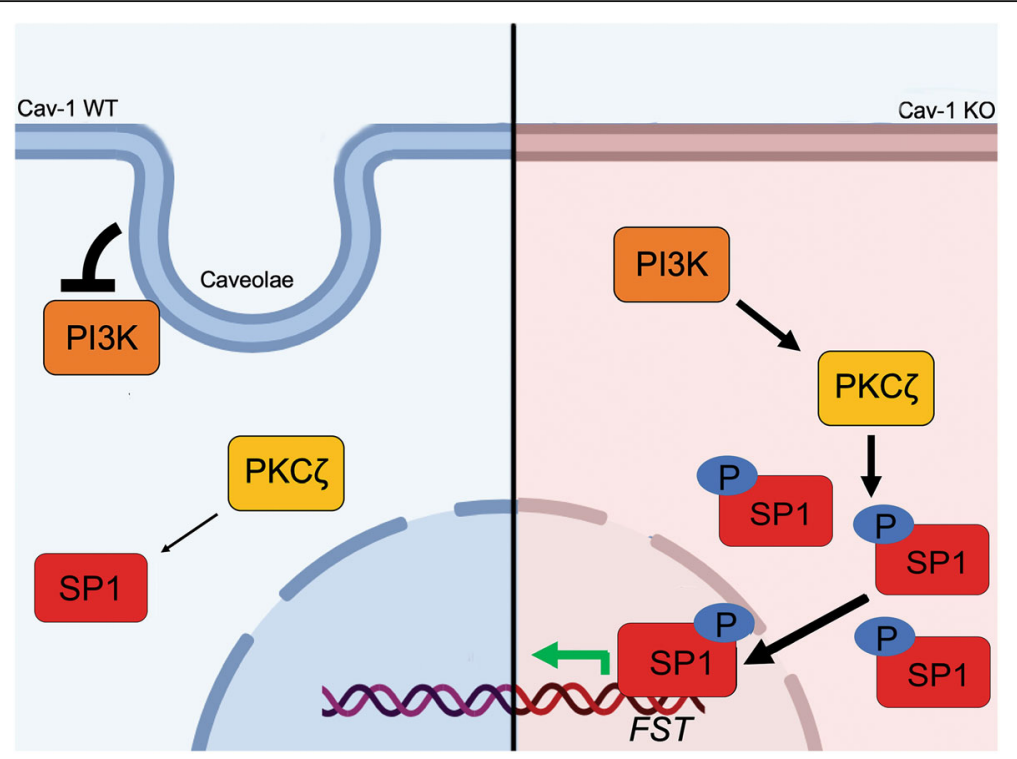

Fig. 7 Proposed molecular mechanism for the regulation of FST by cav-1. In the absence of cav-1/caveolae, enhanced PI3K activity activates PKC which augments Sp1 phosphorylation, nuclear accumulation and activity. This increases Sp1 binding to the -123 bp region of the FST promoter, resulting in elevated FST transcriptional activation and protein expression

modifications such as phosphorylation, acetylation, sumoylation, ubiquitylation, and glycosylation [29]. These can positively or negatively influence Sp1 DNA binding and activity [29]. Since cav-1 is a well-known regulator of a wide variety of intracellular signaling cascades, we initially assessed whether cav-1 deficiency altered Sp1 phosphorylation, the most well described Sp1 post-translational modification. Our results now reveal novel regulation of $\mathrm{Sp} 1$ ser/thr phosphorylation, and hence activation, by cav-1. In seeking to identify the mechanism behind this increased phosphorylation, we further identified augmented activity of PI3K-PKC $\zeta$ signaling in cav-1 deficient $\mathrm{MC}$ as a mediator of this increased Sp1 phosphorylation.

PI3K is a lipid kinase that catalyzes the formation of a family of phosphoinositides, including PIP3, with an important role in cell growth and transformation [44, 45]. Our studies illustrate that cav-1 deficient MC exhibit basally elevated PI3K activity and signaling compared to cav-1 WT cells. Although a few studies have assessed the regulation of PI3K by cav-1, these show discordant effects, likely dependent on cell type. Thus, in cancer cells (HeLa), cav-1 overexpression increased PI3K activity [46], while in fibroblasts the opposite effects were observed [47]. In some studies, while PI3K activity was not assessed directly, downstream signaling was found to be regulated by cav-1. For example, in hepatoma cells, increased cav-1 expression induced by plasmalogens was associated with decreased Akt activity, suggesting inhibitory effects of cav-1 on PI3K [48]. The inhibitory association of cav-1 with p85, the regulatory subunit of PI3K, was suggested to mediate this effect [47]. However, inhibition of PI3K signaling by cav-1 may also occur through an indirect mechanism by augmenting activity of PTEN (phosphatase and tensin homolog). This lipid phosphatase acts as the primary suppressor of PI3K signaling by dephosphorylating PIP3 [49]. Xia et al. demonstrated that cav-1 deficient fibroblasts have lower PTEN activity than their WT counterparts. Cav-1 reconstitution increased PTEN membrane localization and activity, and this was associated with a reduction in signaling downstream of PI3K (Akt activity) [50]. Like PI3K, PTEN was also found to physically interact with cav-1 [50]. These data thus suggest both direct and indirect regulation of PI3K by cav-1, and support our findings that cav-1 represses PI3K activity.

The most well studied mediator of PI3K signaling is the ser/thr kinase Akt. Our data, however, excluded a role for Akt in FST regulation by cav-1. Instead, we identified $\mathrm{PKC}$, , also known to function downstream of $\mathrm{PI} 3 \mathrm{~K}$, as the effector for Sp1 activation and FST upregulation in cav-1 deficient MC. РКC $\zeta$ is a ser/thr kinase which activates $\mathrm{Sp} 1$ through phosphorylation of residues in its zinc region [29, 51, 52]. Unlike most other PKC isoforms, $\mathrm{PKC} \zeta$ is activated without the need for calcium and/or diacylglycerol [53]. Secondary messenger lipids including PIP3 recruit PKC from cytosol to the membrane through binding to its regulatory domain. They can also induce a conformational change that removes auto-inhibition of PKC $\zeta$ catalytic activity [53, 54]. At the membrane, the PI3K-dependent kinase PDK-1 can activate $\mathrm{PKC} \zeta$ through phosphorylation on its activation loop [33]. Similar to several other, but not all, PKC 
isoforms, PKCל was shown to interact with the cav-1 scaffolding domain, a region of cav-1 that mediates its interaction with numerous other proteins $[55,56]$. This interaction was also found to inhibit $\mathrm{PKC \zeta}$ autophosphorylation and kinase activity [55]. Furthermore, PDK1 interaction with cav-1, which reduced its kinase activity, was also found [57]. Cav-1/caveolae thus function at several levels to inhibit $\mathrm{PKC} \zeta$ activation. In disagreement with this, however, PKC localization to caveolae was associated with increased activity in response to the lipid metabolite ceramide, highlighting stimulus specificity for the role of cav-1/caveolae in PKC nally, it should be noted that we also observed elevated PKC transcript levels in cav-1 deficient MC. The mechanism underlying this will be defined in future studies.

Interestingly, while pharmacologic PI3K and PKCל inhibition blunted Sp1 activity, GSK, JNK and p38 inhibition in our studies was found to promote Sp1 activity. In agreement with these findings, these kinases have been individually shown to negatively regulate components of the $\mathrm{PI} 3 \mathrm{~K} / \mathrm{PKC \zeta}$ pathways, which converge to modulate Sp1 activity. For example, in murine microglia cells GSK3 inhibition increased nuclear Sp1 expression and activity along with increased IL-10 production through elevated PI3K activity [59]. In chondrocytes, p38 was shown to bind the regulatory domain of $\mathrm{PKC} \zeta$, preventing its autophosphorylation and thereby inhibiting its activity [60]. Finally, in human lung cancer cells, JNK inhibited Sp1 and thereby its downstream target genes that regulate cell growth [61]. However, in some settings, positive regulation of PI3K/PKC /Sp1 by JNK has been found. For example, in lung epithelial cells JNK increased Sp1 phosphorylation and activity in repose to oxidative stress [62]. In another study, JNK was found to positively regulate PKC through affecting its localization to podosomes [63]. These differences could be attributed to differences in the cell type and stimulus being investigated. Nonetheless, it is likely that these kinases function through modulation of PI3K/ PKC $\zeta$ to affect Sp1 transcriptional activity.

Collectively, our data have thus identified novel regulation of FST transcription by cav-1/caveolae through suppression of $\mathrm{PI} 3 \mathrm{~K} / \mathrm{PKC} / \mathrm{Sp} 1$ signaling. It is noteworthy that in several fibrotic kidney diseases in both rodent models and humans, renal cav-1 expression is elevated [14, 34-36]. This would be expected to attenuate FST expression, thereby inhibiting its protective antifibrotic effect. Therapies to increase activity of $\mathrm{Sp} 1$ or its upstream mediators would thus seem to be of potential therapeutic interest. However, activation of PI3K, PKC $\zeta$ and Sp1 have all also been associated with renal profibrotic effects [64-66]. Indeed, Sp1 was shown to activate the transcription of several profibrotic and matrix protein genes including PAI-1,TGF $\beta 1$, fibronectin, PDGF-BB, $\alpha$-SMA and collagen in various cell types [64, 67-69]. Sp1 was also shown to act synergistically with profibrotic signaling molecules such as Smad3 in response to TGF $\beta 1$ to promote matrix production [70]. Furthermore, inhibition of Sp1 activity using ring-type Sp1 decoy oligonucleotides attenuated kidney fibrosis in the unilateral obstruction model [71]. While these data support a profibrotic role for Sp1, it should be noted that $\mathrm{Sp} 1$ also regulates a concurrent protective response to limit the extent of fibrosis. Thus, Sp1 mediates induction of the antifibrotic protein Smad7 by TGF $\beta 1$ [72], and as our data show, of the antifibrotic protein FST.

Taken together, our data show a novel role for cav-1 in the post-translational regulation of $\mathrm{Sp} 1$ through PI3K/PKCל signaling. Importantly, we established that $\mathrm{Sp} 1$, which has thus far been identified as a profibrotic factor in kidney disease, is a critical transcriptional regulator for the antifibrotic protein FST. Thus, therapeutically targeting enhanced activity of $\mathrm{PI} 3 \mathrm{~K} / \mathrm{PKC} \zeta /$ $\mathrm{Sp} 1$ is not a viable option for the treatment of kidney disease due to potential unwanted profibrotic effects. Future studies should further address the therapeutic potential of FST administration in the treatment of fibrotic kidney disease.

\section{Conclusion}

Our results identified $\mathrm{Sp} 1$ as the critical transcription factor regulating activation of the FST promoter in MC lacking cav-1 through binding to a region within $123 \mathrm{bp}$ of the transcription start site. Absence of cav-1 increases Sp1 transcriptional activity through augmented activation of phosphoinositide 3-kinase (PI3K) and its downstream mediator protein kinase $\mathrm{C}(\mathrm{PKC})$ zeta. In turn, PKC zeta phosphorylates and activates $\mathrm{Sp} 1$. These findings describe a novel transcriptional mechanism regulated by cav-1 which functions to repress the expression of FST, a major antifibrotic protein. These findings provide important knowledge that will inform the development of antifibrotic treatment strategies for chronic kidney disease.

\section{Additional files}

Additional file 1: Table S1. Drugs. Table S2. Plasmids and siRNA Table S3. Antibodies. Table S4. qPCR primers. Table S5. Cloning Sequences. (DOCX $23 \mathrm{~kb}$ )

Additional file 2: Figure S1. (A) Exogenous recombinant FST $(1 \mu \mathrm{g} / \mathrm{ml})$ protects against TGF $\beta 1$ (0.5 ng, $24 \mathrm{~h}$ )-induced extracellular matrix (ECM) production in cav-1 WT MC $(n=2)$. (B) siRNA (50 nM)-mediated FST downregulation augments TGF $\beta 1(0.5 \mathrm{ng}, 24 \mathrm{~h})$-induced ECM production in cav-1 KO MC $(n=2)$. (TIF $29033 \mathrm{~kb})$

Additional file 3: Figure S2. The mRNA expression of FSTL-3 is not significantly different between cav-1 WT and KO MC ( $n=6)$. (TIF 13489 kb)

\section{Abbreviations}

Cav-1: Caveolin-1; FST: Follistatin; KO: Knockout; MC: Mesangial cells; PDK1: Phosphoinositide-dependent protein kinase-1; PH: Pleckstrin homology; PI3K: Phosphoinositide 3-kinase; PIP3: Phosphatidylinositol 3,4,5-

trisphosphate; PKCद: Protein kinase C zeta; PTEN: Phosphatase and tensin 
homolog; ser/thr: Serine/threonine; TGF $\beta$ : Transforming growth factor beta; TSS: Transcription start site; WGA: Wheat germ agglutinin; WT: Wild-type

\section{Acknowledgements}

We acknowledge the support of St. Joseph's Healthcare for nephrology research. We thank Dr. J. Yoon for providing mFST4-FL luciferase construct, Dr. P. Di for providing 3xmt SP1 luciferase construct, Dr. J. Clifford for providing CMV-GST-SP1-HA construct and Dr. N. Gautam (Addgene plasmid \# 85223) for providing PH Akt-Venus construct.

\section{Funding}

This work was supported by the Canadian Institutes of Health Research (CIHR) (JCK), MOP 136868 and Kidney Foundation of Canada (JCK), KFOC160011. NM is the recipient of a studentship award from the Research Institute of St. Joe's Hamilton.

\section{Availability of data and materials}

All data generated or analyzed during this study are included in this published article.

\section{Authors' contributions}

NM, DZ, RL, TW, AG, PP performed experiments and analysed data. NM wrote the manuscript. NM and JCK conceived the ideas. JCK edited the manuscript. BG assisted with animal studies. All authors read and approved the final manuscript.

\section{Ethics approval and consent to participate} N/A.

\section{Competing interests}

The authors declare that they have no competing interests.

\section{Publisher's Note}

Springer Nature remains neutral with regard to jurisdictional claims in published maps and institutional affiliations.

\section{Author details}

'Division of Nephrology, Department of Medicine, McMaster University, Hamilton, Canada. ${ }^{2}$ Physiological Sciences Graduate Program, Health Sciences Centre, Federal University of Espirito Santo, Vitoria, Brazil. ${ }^{3}$ St. Joseph's Hospital, 50 Charlton Ave East, Rm T3311, Hamilton, ON L8N 4A6, Canada.

Received: 8 February 2019 Accepted: 3 April 2019

Published online: 17 April 2019

\section{References}

1. Johnson RJ, Floege J, Yoshimura A, lida H, Couser WG, Alpers CE. The activated mesangial cell: a glomerular "myofibroblast"? J Am Soc Nephrol. 1992:2:S190-7.

2. Schlöndorff $D$, Banas B. The mesangial cell revisited: no cell is an island. J Am Soc Nephrol. 2009;20:1179-87. https://doi.org/10.1681/ASN.2008050549.

3. Schlöndorff D. The glomerular mesangial cell: an expanding role for a specialized pericyte. FASEB J. 1987;1:272-81.

4. Schlöndorff D. Roles of the mesangium in glomerular function. Kidney Int. 1996;49:1583-5. https://doi.org/10.1038/ki.1996.229.

5. Riser BL, Cortes P, Zhao X, Bernstein J, Dumler F, Narins RG. Intraglomerular pressure and mesangial stretching stimulate extracellular matrix formation in the rat. J Clin Invest. 1992;90:1932-43. https://doi.org/10.1172/JCI116071.

6. Floege J, Radeke HR, Johnson RJ. Glomerular cells in vitro versus the glomerulus in vivo. Kidney Int. 1994;45:360-8. https://doi.org/10.1038/ki.1994.46.

7. Liu Y. Cellular and molecular mechanisms of renal fibrosis. Nat Rev Nephrol. 2011;7:684-96. https://doi.org/10.1038/nrneph.2011.149.

8. Machado FS, Rodriguez NE, Adesse D, Garzoni LR, Lisanti MP, Burk RD, Albanese C, Van K, Weiss LM, Nagajyothi F, Nosanchuk JD, Mary E. Caveolins and Caveolae. 2012;729:65-82. https://doi.org/10.1007/978-1-4614-1222-9.

9. Fridolfsson HN, Roth DM, Insel PA, Patel HH. Regulation of intracellular signaling and function by caveolin. FASEB J. 2014;28:3823-31. https://doi. org/10.1096/fj.14-252320
10. van Krieken R, Krepinsky JC. Caveolin-1 in the pathogenesis of diabetic nephropathy: potential therapeutic target? Curr Diab Rep. 2017;17. https:// doi.org/10.1007/s1 1892-017-0844-9.

11. Guan TH, Chen G, Gao B, Janssen MR, Uttarwar L, Ingram AJ, Krepinsky JC. Caveolin-1 deficiency protects against mesangial matrix expansion in a mouse model of type 1 diabetic nephropathy. Diabetologia. 2013;56:206877. https://doi.org/10.1007/s00125-013-2968-z.

12. Zhang B, Peng F, Wu D, Ingram AJ, Gao B, Krepinsky JC. Caveolin-1 phosphorylation is required for stretch-induced EGFR and Akt activation in mesangial cells. Cell Signal. 2007;19:1690-700. https://doi.org/10.1016/j. cellsig.2007.03.005.

13. Peng F, Zhang B, Wu D, Ingram AJ, Gao B, Krepinsky JC. TGFbeta-induced RhoA activation and fibronectin production in mesangial cells require caveolae. Am J Physiol Renal Physiol. 2008;295:F153-64. https://doi.org/10. 1152/ajprenal.00419.2007.

14. Sindhu RK, Ehdaie A, Vaziri ND, Roberts CK. Effects of chronic renal failure on caveolin-1, guanylate cyclase and AKT protein expression. Biochim Biophys Acta. 2004;1690:231-7. https://doi.org/10.1016/j.bbadis.2004.06.013.

15. Hedger MP, De Kretser DM. The activins and their binding protein, follistatin-diagnostic and therapeutic targets in inflammatory disease and fibrosis. Cytokine Growth Factor Rev. 2013;24:285-95. https://doi.org/10. 1016/j.cytogfr.2013.03.003.

16. de Kretser DM, O'Hehir RE, Hardy CL, Hedger MP. The roles of activin a and its binding protein, follistatin, in inflammation and tissue repair. Mol Cell Endocrinol. 2012;359:101-6. https://doi.org/10.1016/j.mce.2011.10.009.

17. Aoki F, Kurabayashi M, Hasegawa Y, Kojima I. Attenuation of bleomycininduced pulmonary fibrosis by follistatin. Am J Respir Crit Care Med. 2005; 172:713-20. https://doi.org/10.1164/rccm.200412-16200C

18. Patella S, Phillips DJ, Tchongue J, de Kretser DM, Sievert W. Follistatin attenuates early liver fibrosis: effects on hepatic stellate cell activation and hepatocyte apoptosis. Am J Physiol Gastrointest Liver Physiol. 2006;290: G137-44. https://doi.org/10.1152/ajpgi.00080.2005.

19. Maeshima A, Mishima K, Yamashita S, Nakasatomi M, Miya M, Sakurai N, Sakairi T, Ikeuchi H, Hiromura K, Hasegawa Y, Kojima I, Nojima Y. Follistatin, an activin antagonist, ameliorates renal interstitial fibrosis in a rat model of unilateral uretera obstruction. Biomed Res Int. 2014:2014. https://doi.org/10.1155/2014/376191.

20. Li R, Wang T, Walia K, Gao B, Krepinsky JC. Regulation of profibrotic responses by ADAM17 activation in high glucose requires its $C$-terminus and FAK. J Cell Sci. 2018;131:jcs208629. https://doi.org/10.1242/jcs.208629.

21. Neill PRO, Kalyanaraman V, Gautam N, Louis S. Subcellular optogenetic activation of Cdc42 controls local and distal signaling to drive immune cell migration. 2016:1442-50. https://doi.org/10.1091/mbc.E15-12-0832.

22. Evans LW, Muttukrishna S, Groome NP. Development, validation and application of an ultra-sensitive two-site enzyme immunoassay for human follistatin. J Endocrinol. 1998;156:275-82. https://doi.org/10.1677/joe.0.1560275.

23. Saito S, Sidis $Y$, Mukherjee A, Xia Y, Schneyer A. Differential biosynthesis and intracellular transport of follistatin isoforms and follistatin-like-3. Endocrinology. 2005;146:5052-62. https://doi.org/10.1210/en.2005-0833.

24. Suginos K, Kurosawas N, Nakamuras T, Takios K, Lingll N, Titanill K. Molecular heterogeneity of Follistatin, an Activin-binding protein. J Biol Chem. 1993; 268:15579-87.

25. de Kretser DM, Hedger MP, Loveland KL, Phillips DJ. Inhibins, activins and follistatin in reproduction. Hum Reprod Update. 2002:8:529-41. https://doi. org/10.1093/humupd/8.6.529.

26. De Groot E, Veltmaat J, Caricasole A, Defize L, Van Den Eijnden-van Raaij A Cloning and analysis of the mouse follistatin promoter. Mol Biol Rep. 2000; 27:129-39. https://doi.org/10.1023/A:1007159031000.

27. Messeguer X, Escudero R, Farré D, Núñez O, Martínez J, Albà MM. PROMO: detection of known transcription regulatory elements using species-tailored searches. Bioinformatics. 2002;18:333-4 http://www.ncbi.nlm.nih.gov/ pubmed/11847087 (Accessed 11 Apr 2016)

28. Necela BM, Su W, Thompson EA. Peroxisome proliferator-activated receptor gamma down-regulates follistatin in intestinal epithelial cells through SP1. J Biol Chem. 2008:283:29784-94. https://doi.org/10.1074/jbc.M804481200.

29. Tan NY, Khachigian LM. Sp1 phosphorylation and its regulation of gene transcription. Mol Cell Biol. 2009:29:2483-8. https://doi.org/10.1128/MCB.01828-08.

30. Zhang Y, Liao M, Dufau ML. Phosphatidylinositol 3-kinase/protein kinase Czeta-induced phosphorylation of Sp1 and p107 repressor release have a critical role in histone deacetylase inhibitor-mediated derepression of transcription of the luteinizing hormone receptor gene. Mol Cell Biol. 2006; 26:6748-61. https://doi.org/10.1128/MCB.00560-06. 
31. Walker EH, Pacold ME, Perisic O, Stephens L, Hawkins PT, Wymann MP Williams RL. Structural determinants of phosphoinositide 3-kinase inhibition by wortmannin, LY294002, quercetin, myricetin, and staurosporine. Mol Cell. 2000;6:909-19 http://www.ncbi.nlm.nih.gov/pubmed/11090628 (Accessed 26 Mar 2019).

32. Yu JSL, Cui W. Proliferation, survival and metabolism: the role of PI3K/AKT/ mTOR signalling in pluripotency and cell fate determination. Development. 2016;143:3050-60. https://doi.org/10.1242/dev.137075.

33. Chou MM, Hou W, Johnson J, Graham LK, Lee MH, Chen C-S, Newton AC, Schaffhausen BS, Toker A. Regulation of protein kinase C C by PI 3-kinase and PDK-1. Curr Biol. 1998;8:1069-78. https://doi.org/10.1016/S09609822(98)70444-0.

34. Moriyama T, Tsuruta Y, Shimizu A, Itabashi M, Takei T, Horita S, Uchida K, Nitta K. The significance of caveolae in the glomeruli in glomerular disease. J Clin Pathol. 2011;64:504-9. https://doi.org/10.1136/jcp.2010.087023.

35. Tamai O, Oka N, Kikuchi T, Koda Y, Soejima M, Wada Y, Fujisawa M, Tamaki K, Kawachi H, Shimizu F, Kimura H, Imaizumi T, Okuda S. Caveolae in mesangial cells and caveolin expression in mesangial proliferative glomerulonephritis. Kidney Int. 2001;59:471-80. https://doi.org/10.1046/J. 1523-1755.2001.059002471.X.

36. Komers R, Schutzer WE, Reed JF, Lindsley JN, Oyama TT, Buck DC, Mader SL, Anderson S. Altered endothelial nitric oxide synthase targeting and conformation and Caveolin-1 expression in the diabetic kidney. Diabetes. 2006;55:1651-9. https://doi.org/10.2337/db05-1595.

37. Kim S, Lee Y, Seo JE, Cho KH, Chung JH. Caveolin-1 increases basal and TGF31 -induced expression of type I procollagen through PI-3 kinase/Akt/mTOR pathway in human dermal fibroblasts. Cell Signal. 2008;20:1313-9. https:// doi.org/10.1016/j.cellsig.2008.02.020

38. Wang X, Shi L, Han Z, Liu B. Follistatin-like 3 suppresses cell proliferation and fibronectin expression via p38MAPK pathway in rat mesangial cells cultured under high glucose. Int J Clin Exp Med. 2015;8:15214-21.

39. Sidis Y, Tortoriello DV, Holmes WE, Pan Y, Keutmann HT, Schneyer AL. Follistatin-related protein and Follistatin differentially neutralize endogenous vs. exogenous Activin. Endocrinology. 2002;143:1613-24. https://doi.org/10. 1210/endo.143.5.8805.

40. Tsuchida K, Arai KY, Kuramoto Y, Yamakawa N, Hasegawa Y, Sugino H. Identification and characterization of a novel Follistatin-like protein as a binding protein for the TGF- $\beta$ family. J Biol Chem. 2000;275:40788-96. https://doi.org/10.1074/jbc.M006114200.

41. Willert J, Epping M, Pollack JR, Brown PO, Nusse R. A transcriptional response to Wnt protein in human embryonic carcinoma cells. BMC Dev Biol. 2002;2:8 http://www.ncbi.nlm.nih.gov/pubmed/12095419 (Accessed 29 Nov 2018.

42. Bartholin L, Maguer-Satta V, Hayette S, Martel S, Gadoux M, Corbo L, Magaud JP. Transcription activation of FLRG and follistatin by activin a, through Smad proteins, participates in a negative feedback loop to modulate activin a function. Oncogene. 2002;21:2227-35. https://doi.org/10. 1038/sj.onc.1205294.

43. Miyanaga K, Shimasaki S. Structural and functional characterization of the rat follistatin (activin-binding protein) gene promoter. Mol Cell Endocrinol. 1993;92:99-109 http://www.ncbi.nlm.nih.gov/pubmed/8472873 (Accessed 29 Nov 2018).

44. Vara JÁF, Casado E, de Castro J, Cejas P, Belda-Iniesta C, González-Barón M. PI3K/Akt signalling pathway and cancer. Cancer Treat Rev. 2004;30:193-204. https://doi.org/10.1016/j.ctrv.2003.07.007.

45. Fruman DA, Chiu H, Hopkins BD, Bagrodia S, Cantley LC, Abraham RT. The PI3K pathway in human disease. Cell. 2017;170:605-35. https://doi.org/10. 1016/j.cell.2017.07.029

46. Shack S, Wang X-T, Kokkonen GC, Gorospe M, Longo DL, Holbrook NJ. Caveolin-induced activation of the phosphatidylinositol 3-kinase/Akt pathway increases arsenite cytotoxicity. Mol Cell Biol. 2003;23:2407-14 http://www.ncbi.nlm.nih.gov/pubmed/12640124 (Accessed 21 Dec 2018).

47. Zundel W, Swiersz LM, Giaccia A. Caveolin 1-mediated regulation of receptor tyrosine kinase-associated phosphatidylinositol 3-kinase activity by ceramide. Mol Cell Biol. 2000;20:1507-14 http://www.ncbi.nlm.nih.gov/ pubmed/10669728 (Accessed 21 Dec 2018).

48. Zhan Y, Wang L, Liu J, Ma K, Liu C, Zhang Y, Zou W. Choline Plasmalogens isolated from swine liver inhibit hepatoma cell proliferation associated with Caveolin-1/Akt signaling. PLoS One. 2013;8. https://doi.org/10.1371/journal. pone.0077387.

49. Chalhoub N, Baker SJ. PTEN and the PI3-kinase pathway in cancer. Annu Rev Pathol. 2009;4:127-50. https://doi.org/10.1146/annurev.pathol.4.110807.092311.
50. Xia H, Khalil W, Kahm J, Jessurun J, Kleidon J, Henke CA. Pathologic Caveolin-1 regulation of PTEN in idiopathic pulmonary fibrosis. Am J Pathol. 2010;176:2626-37. https://doi.org/10.2353/ajpath.2010.091117.

51. Tan NY, Midgley VC, Kavurma MM, Santiago FS, Luo X, Peden R, Fahmy RG, Berndt MC, Molloy MP, Khachigian LM. Angiotensin II-inducible plateletderived growth factor-D transcription requires specific Ser/Thr residues in the second zinc finger region of Sp1. Circ Res. 2008;102:e38-51. https://doi. org/10.1161/CIRCRESAHA.107.167395.

52. Pal S, Claffey KP, Cohen HT, Mukhopadhyay D. Activation of Sp1-mediated vascular permeability factor/vascular endothelial growth factor transcription requires specific interaction with protein kinase C zeta. J Biol Chem. 1998; 273:26277-80. https://doi.org/10.1074/JBC.273.41.26277.

53. Hirai T, Chida K. Protein kinase C (PKC)): activation mechanisms and cellular functions. J Biochem. 2003;133:1-7. https://doi.org/10.1093/jb/mvg017.

54. Standaert ML, Bandyopadhyay G, Kanoh Y, Sajan MP, Farese RV. Insulin and PIP3 activate PKC-zeta by mechanisms that are both dependent and independent of phosphorylation of activation loop (T410) and autophosphorylation (T560) sites. Biochemistry. 2001;40:249-55 http://www. ncbi.nlm.nih.gov/pubmed/11141077 (Accessed 31 July 2018).

55. Oka N, Yamamoto M, Schwencke C, Kawabe Jl, Ebina T, Ohno S, Couet J, Lisanti MP, Ishikawa Y. Caveolin interaction with protein kinase C. isoenzyme-dependent regulation of kinase activity by the caveolin scaffolding domain peptide. J Biol Chem. 1997;272:33416-21. https://doi. org/10.1074/jbc.272.52.33416

56. Couet J, Li S, Okamoto T, Ikezu T, Lisanti MP. Identification of peptide and protein ligands for the caveolin-scaffolding domain. Implications for the interaction of caveolin with caveolae-associated proteins. J Biol Chem. 1997; 272:6525-33. https://doi.org/10.1074/JBC.272.10.6525.

57. Chun J, Kwon T, Lee EJ, Hyun S, Hong S-K, Kang SS. The subcellular localization of 3-phosphoinositide-dependent protein kinase is controlled by caveolin-1 binding. Biochem Biophys Res Commun. 2004;326:136-46. https://doi.org/10.1016/j.bbrc.2004.10.208.

58. Fox TE, Houck KL, O'Neill SM, Nagarajan M, Stover TC, Pomianowski PT, Unal O, Yun JK, Naides SJ, Kester M. Ceramide recruits and activates protein kinase C ( (PKC) within structured membrane microdomains. J Biol Chem. 2007;282:12450-7. https://doi.org/10.1074/jbc.M700082200.

59. Huang W-C, Lin Y-S, Wang C-Y, Tsai C-C, Tseng H-C, Chen C-L, Lu P-J, Chen P-S, Qian L, Hong J-S, Lin C-F. Glycogen synthase kinase-3 negatively regulates antiinflammatory interleukin-10 for lipopolysaccharide-induced iNOS/NO biosynthesis and RANTES production in microglial cells. Immunology. 2009;128: e275-86. https://doi.org/10.1111/j.1365-2567.2008.02959.x.

60. Kim J-S, Park Z-Y, Yoo Y-J, Yu S-S, Chun J-S. p38 kinase mediates nitric oxide-induced apoptosis of chondrocytes through the inhibition of protein kinase C $\zeta$ by blocking autophosphorylation. Cell Death Differ. 2005;12:20112. https://doi.org/10.1038/sj.cdd.4401511.

61. Wu J, Zhao S, Tang Q, Zheng F, Chen Y, Yang L, Yang X, Li L, Wu W, Hann SS. Activation of SAPK/JNK mediated the inhibition and reciprocal interaction of DNA methyltransferase 1 and EZH2 by ursolic acid in human lung cancer cells. J Exp Clin Cancer Res. 2015;34:99. https://doi.org/10.1186/ s13046-015-0215-9.

62. Chu S, Ferro TJ. Identification of a hydrogen peroxide-induced PP1-JNK1Sp1 signaling pathway for gene regulation. Am J Physiol Cell Mol Physiol. 2006:291:L983-92. https://doi.org/10.1152/ajplung.00454.2005.

63. Xiao $H$, Bai X-H, Wang Y, Kim H, Mak AS, Liu M. MEK/ERK pathway mediates PKC activation-induced recruitment of PKC $\zeta$ and MMP-9 to podosomes. J Cell Physiol. 2013;228:416-27. https://doi.org/10.1002/jcp.24146.

64. Motojima M, Ando T, Yoshioka T. Sp1-like activity mediates angiotensin-IIinduced plasminogen-activator inhibitor type-1 (PAl-1) gene expression in mesangial cells. Biochem J. 2000;349:435-41 http://www.ncbi.nlm.nih.gov/ pubmed/10880342 (Accessed 21 Dec 2018).

65. Kikkawa R, Haneda M, Uzu T, Koya D, Sugimoto T, Shigeta Y. Translocation of protein kinase $\mathrm{C}$ alpha and zeta in rat glomerular mesangial cells cultured under high glucose conditions. Diabetologia. 1994;37:838-41 http://www.ncbi.nlm.nih.gov/pubmed/7988787 (Accessed 21 Dec 2018).

66. Xia L, Wang H, Munk S, Kwan J, Goldberg HJ, Fantus IG, Whiteside Cl. High glucose activates PKC- $\zeta$ and NADPH oxidase through autocrine TGF- $\beta_{1}$ signaling in mesangial cells. Am J Physiol Physiol. 2008;295:F1705-14. https://doi.org/10.1152/ajprenal.00043.2008.

67. Chen H, Zhou Y, Chen KQ, An G, Ji SY, Chen QK. Anti-fibrotic effects via regulation of transcription factor $\mathrm{Sp} 1$ on hepatic stellate cells. Cell Physiol Biochem. 2012;29:51-60. https://doi.org/10.1159/000337586. 
68. Kum Y-S, Kim K-H, Park T-I, Suh I-S, Oh H-K, Cho C-H, Park J-B, Chang Y-C, Park J-H, Lee K-G, Park K-K. Antifibrotic effect via the regulation of transcription factor Sp1 in lung fibrosis. Biochem Biophys Res Commun. 2007;363:368-74. https://doi.org/10.1016/J.BBRC.2007.08.176.

69. Kang JH, Chae Y-M, Park K-K, Kim C-H, Lee I-S, Chang Y-C. Suppression of mesangial cell proliferation and extracellular matrix production in streptozotocin-induced diabetic rats by Sp1 decoy oligodeoxynucleotide in vitro and in vivo. J Cell Biochem. 2008;103:663-74. https://doi.org/10.1002/ jcb.21440.

70. Poncelet AC, Schnaper HW. Sp1 and Smad proteins cooperate to mediate transforming growth factor-beta 1-induced alpha 2(I) collagen expression in human glomerular mesangial cells. J Biol Chem. 2001;276:6983-92. https:// doi.org/10.1074/jbc.M006442200.

71. Chae Y-M, Park K-K, Lee I-K, Kim J-K, Kim C-H, Chang Y-C. Ring-Sp1 decoy oligonucleotide effectively suppresses extracellular matrix gene expression and fibrosis of rat kidney induced by unilateral ureteral obstruction. Gene Ther. 2006:13:430-9. https://doi.org/10.1038/s.gt.3302696.

72. Brodin G, Ångren A, ten Dijke P, Heldin C-H, Heuchel R. Efficient TGF- $\beta$ induction of the Smad7 gene requires cooperation between AP-1, Sp1, and Smad proteins on the mouse Smad7 promoter. J Biol Chem. 2000;275: 29023-30. https://doi.org/10.1074/jbc.M002815200.

Ready to submit your research? Choose BMC and benefit from:

- fast, convenient online submission

- thorough peer review by experienced researchers in your field

- rapid publication on acceptance

- support for research data, including large and complex data types

- gold Open Access which fosters wider collaboration and increased citations

- maximum visibility for your research: over $100 \mathrm{M}$ website views per year

At BMC, research is always in progress.

Learn more biomedcentral.com/submissions 